\title{
EMPLEO DE LAS ARMAS ARROJADIZAS DEL ÁREA CENTRO-ANDINA: ¿ARMAS DE CAZA O DE GUERRA?
}

\author{
VINCENT CHAMUSSYi \\ INVESITAGADOR ASOCIADO A CNRS - UNIVERSITÉ PARIS | \\ chamussy@wanadoo.fr
}

\section{RESUMEN}

Todos los tipos de armas no se utilizaron de la misma manera y al mismo tiempo durante la prehistoria del área centro-andina. El estudio de su invención o re-invención (o primera ocurrencia en una parte dada del mundo, lo cual es casi sinónimo), su uso y su evolución, que nunca ha sido hecho de forma completa hasta la fecha, proporciona informaciones fundamentales sobre las sociedades que las utilizaron, sus relaciones mutuas y su medio ambiente. No obstante, la dificultad de diferenciar las armas de guerra de las de cacería y de las herramientas es recurrente. Entre las armas arrojadizas, sostenemos que la mayoría ha sido usada para la caza y el ritual, y que pocas han sido empleadas como armas de guerra hasta los Incas.

Palabras Clave: Andes, armas, guerra, caza, herramienta, símbolo.

\begin{abstract}
All types of weapons were not used in the same way and at the same time during the prehistory of the Central Andean Area. The study of their invention, or re-invention (or first occurrence, which is almost the same), use and evolution which has never been carried out so far, brings us crucial information on the type of society who used them, their mutual relationship and with their environment. Nevertheless, the difficulty to distinguish between war weapons, hunting weapons and domestic tools is recurrent. Among throwing weapons, we contend that most of them have been used for hunting and ritual and few have been used for war till the Incas.
\end{abstract}

KEYwORDS: Andes, warfare, weapons, hunting, tool, symbol.

i Docteur en archéologie précolombienne. Chercheur associé CNRS- Université Paris I. Archéologie des Amériques, UMR 8086. 
La comparación entre las armas del Precerámico con aquellas descritas por los cronistas del siglo XVI saca a relucir que las armas más usadas en el área centro-andina -ver mapa adjunto- no han evolucionado mucho hasta la llegada de los españoles. Así, es a veces difícil determinar si un propulsor, una honda una hacha de piedra provienen del Precerámico o de la época Inca, tal como lo atestiguan los ejemplares conservados en el Museo Nacional de Arqueología Antropología y Historia (MNAAH) de Pueblo Libre. La mayor innovación fue el uso del metal en reemplazo de la piedra, aunque éste nunca fue sistemático; se encuentran armas de piedra y de madera hasta la época Inca. Los motivos de este uso limitado pueden ser culturales (el metal era considerado como símbolo divino) o tecnológico (desconocimiento del hierro). Pero ciertas armas -tales como el arco o la boleadora- aparecieron de forma tardía, quizás por imitación de las poblaciones conquistadas por los Incas.

Las armas ofensivas pueden ser clasificadas en tres categorías: las armas "de estoque", principalmente representadas por los mazos y sus variantes, así como las lanzas, las armas "de corte" (hachas, puñales y cuchillos), y las armas arrojadizas que comprenden las piedras redondas lanzadas con hondas o con la mano, la jabalina o azagaya lanzada con la mano y el venablo lanzado mediante un propulsor (estólica), la flecha lanzada con arco, las cerbatanas, la "bola" lanzada con "boleadoras", y las rocas o "galgas" que se dejaban rodar cuesta abajo sobre los enemigos. Todas estas armas podrían haber servido para la caza y para la guerra, y varias de ellas, como herramientas. Para describirlas, disponemos de tres fuentes de información: la evidencia arqueológica, la iconografía y los cronistas (en lo que se refiere a los periodos más tardíos), los cuales revisaremos -para cada tipo de arma- en este orden por periodo (Tabla 1 cronología adjunta) y por área.

Tabla 1. Cronología. Adoptamos la carta cronolígica de Rowe (1960: 628-631; 1962a: 40-54) y Menzel, Rowe y Dawson (1964), completamentada por Lanning (1967: 25) La fechas son advertidas a.C. o d.C. sin calibración:

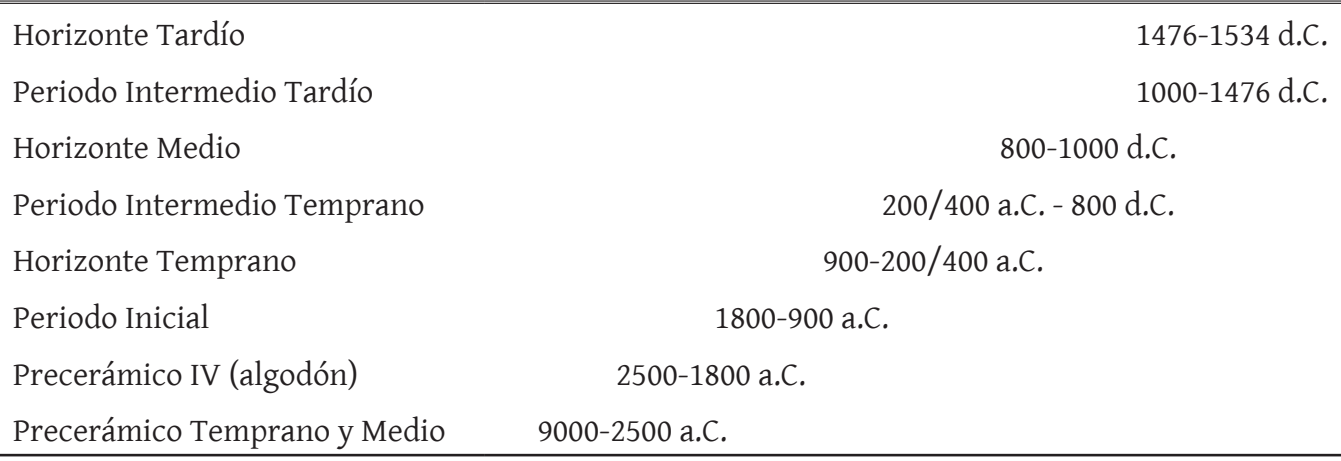

Los descubrimientos arqueológicos de armas son escasos en el Precerámico, y consisten esencialmente en armas de caza. Siguen siendo poco numerosos para el periodo Inicial, pero su cantidad aumenta luego regularmente desde el final del Horizonte Temprano hasta alcanzar su más alto nivel entre los Incas. Quizás la frecuencia de armas sea el mejor criterio para evaluar la importancia de la guerra en los diferentes periodos, considerando además que por antonomasia el material más frecuentemente utilizado (piedra y metal) no es perecedero, más aún porque las armas -siendo más comúnmente objetos compuestos (mazas, hondas, hachas de piedra o de metal con mango, flechas, azagayas, o venablos con armadura de piedra o de metal)-, pueden a menudo ser reconstituidas a partir de estos restos.

Las representaciones iconográficas de armas se encuentran en todos los periodos, pero su frecuencia y el material en que se las representa cambia: durante el periodo Inicial y el Horizonte Temprano, estas representaciones tienen un alcance ideológico. Al comienzo del periodo Intermedio Temprano, 


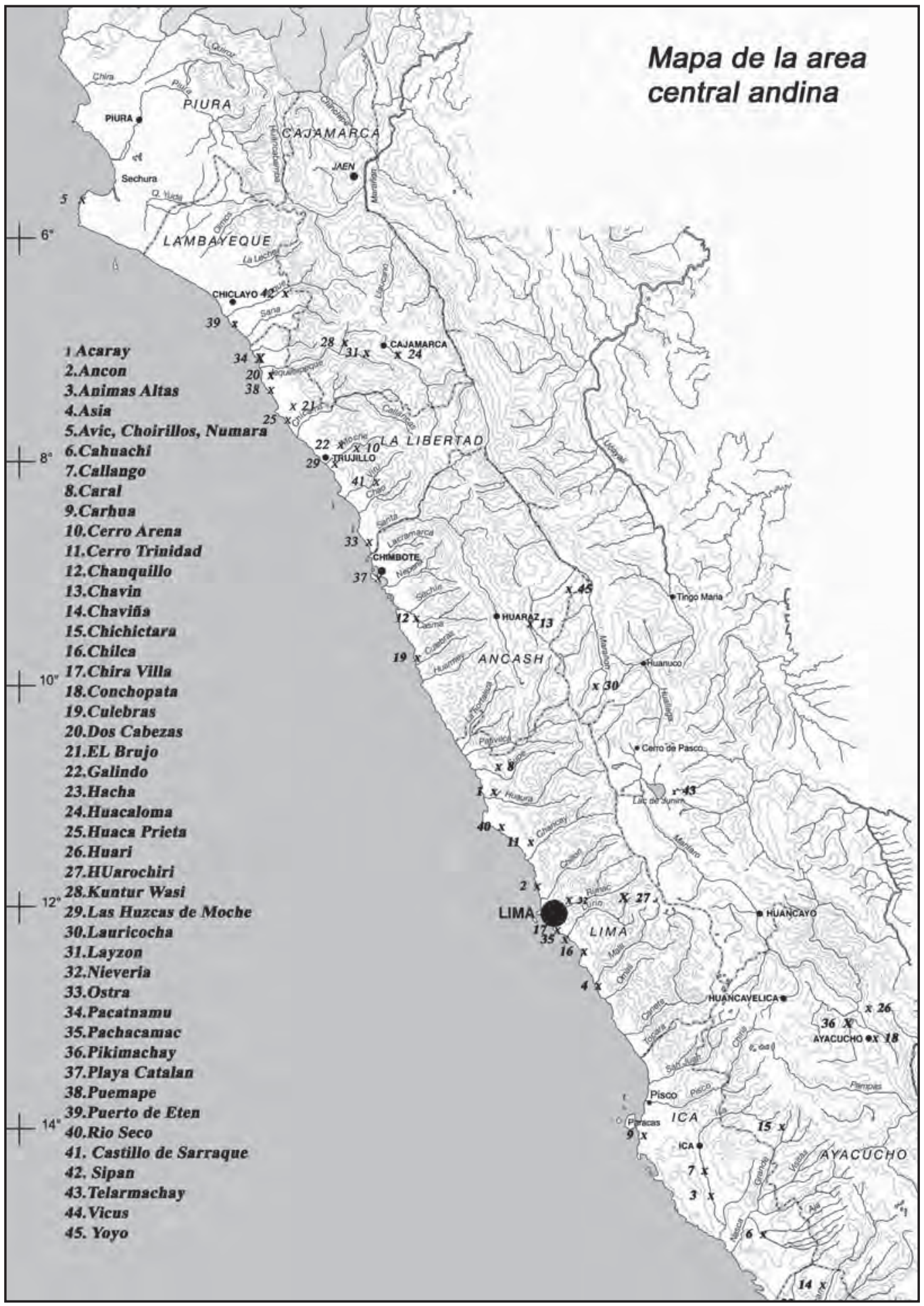

Mapa del área central andina. 
su frecuencia disminuye en el norte y el centro, paralelamente a los temas ideológicos. Pero entre los Mochicas, recobran importancia con el advenimiento de una nueva ideología ampliamente retomada de Chavín; se las encuentra esencialmente en la cerámica o en los muros de adobe. En la sierra (Recuay), la piedra domina, con numerosas figuras de guerrero grabadas o esculpidas en alto relieve. En el sur, los temas ideológicos se prolongan durante el final de Paracas y el inicio de Nasca, pero se vuelven más profanos y naturalistas hacia la mitad del desarrollo Nasca; las divinidades armadas son remplazadas por imágenes de guerreros. El material de base sigue siendo -en su mayoría- textil, pero la importancia de la iconografía plasmada sobre cerámica se incrementa. Durante los desarrollos culturales siguientes (Lima, Lambayeque, Wari, Chimú, Incas), las representaciones guerreras son más escasas pues posiblemente no se las considera tan útiles para la manipulación ideológica como en los periodos anteriores.

Las descripciones escritas por los cronistas se refieren básicamente al Horizonte Tardío, pero ciertos autores sugieren que se puede llegar hasta más atrás en el pasado. Un fragmento de Bartolomé de las Casas (1550), describe un periodo antiguo que Donnan (1978: 87) considera ser el periodo Intermedio Temprano (400/200 a.C.-700 d.C.): "Las armas suyas principales eran hondas; no tenian flechas ni arcos, mas de unas como rodelas para se defender de las piedras. Esto era en la gentes de las sierras; pero en los llanos que llamaban yungas, peleaban algunos con flechas sin yerba: en otras partes con dardos hechos de unas cañahejas, $y$ en lugar de caxquillos, puntas de palmas o de güeso, y tirabanlos con amiento, los cuales eran en tirallos muy diestros y certeros". Guamán Poma (1613: 64) enumera las armas de los guerreros asociados a la tormentosa época del periodo Intermedio Tardío, llamada en quechua "auqua runa", que marcó la desintegración de los estados del Horizonte Medio: "[...] y peleanban con armas que ellos les llamaban chasca chuqui, zuchac chuqui sacmana [lanzas], chambi [mazas], uaraca [honda], conca cuchona, ayri uallcanca [hacha], pura pura [pectoral de metal], uma chuco [casco], uaylla quepa [trompeta de caracol], antara [zampoña]. $Y$ con estas armas se uencían y auía muy mucha muerte y derramamiento de sangre hasta cautiuarze."

\section{¿Cómo diferenciar un arma de GUerRa DE UNA ARMA DE CAZA O DE UNA HERRAMIENTA?}

La cuestión de la origen de la caza sobre la guerra en la historia de la humanidad (Leroi-Gourhan 1964: 236-37) o de la perennidad de la guerra (Clastres [1977] 1997: 24) queda aún para resolver. En el primero caso, las armas de caza habrían sido desviadas de su uso originario con la finalidad de ser empleadas como armas de guerra -de lo cual contamos con un ejemplo conformado por los boleadoras, inicialmente utilizadas por los patagonios para la caza del ñandu o del guanaco, antes de ser utilizadas por los incas en contra de los españoles- lo cual no resuelve la dificultad recurrente de diferenciar un arma de guerra de un arma de caza. No existe algún criterio, único y definitivo, en ese sentido sino más bien, una serie de pistas que permiten optar por una u otra posibilidad:

1. Representación iconográfica

Es nuestra primera fuente, siempre y cuando se la interpreta correctamente, guardándose de caer en las deformaciones ideológicas inducidas por la iconografía.

2. El tipo de sociedad

Dependiendo de su eventual estatuto guerrero, permitirá deducir -hasta cierto punto- el papel de las armas (percatándose de no caer en razonamientos circulares). En el caso de la área centro-andina, hemos defendido la tesis -a través de toda una serie de argumentos- según la cual la guerra era desconocida hasta la etapa más tardía del Horizonte Temprano (Chamussy 2009). En este caso, se podría deducir que las armas halladas antes de este momento tenían un destino cinegenético más que guerrero.

3. Ethnohistoria y etnología

Los relatos de los cronistas y las descripciones de los etnólogos nos ofrecen indicaciones valiosas que nos permiten -en ciertos casos-, extraer inferencias acerca de épocas más remotas. 
4. Contexto del descubrimiento

- Una punta de flecha clavada en un esqueleto humano sugiere, desde luego, un arma de guerra; lo mismo dentro o al lado de los restos de un animal evoca un arma de caza en el caso de acompañar en la tumba a un cazador, un pescador o a un guerrero.

- Al hallarse piedras redondas en parapetos o en campos de batalla, existen fuertes posibilidades para que se trate de municiones de guerra, y para que las hondas sean armas de guerra. De la misma manera, las puntas de flecha sin huellas de uso que se encuentran en grandes cantidades alrededor de ciertos sitios fortificados son probablemente el resultado de combates. A la inversa, si bien se encuentran difícilmente las municiones empleadas en la caza -piedras redondas o puntas de flechas- puede darse el caso de encontrar puntas de piedra o boleadoras cerca de restos de camélidos no domesticados; se tiene luego posiblemente la prueba de que se trata de armas de caza. Piedras redondas con ranura equinoccial, cerca de los restos de redes pueden considerarse como ser pesos. Las piedras redondas encontradas cerca de hogueras sugieren herramientas para machacar vegetales, pulir o bruñir puntas de piedra.

5. Morfología del arma

- Forma y dimensión: es el caso de las puntas Paiján, probablemente utilizadas como armazones de arpones o para la caza de cérvidos. La forma de los arpones los distingue de las azagayas o de los dardos.

- Depende del tamaño del objeto (siendo las armazones proporcionales al porte del animal, ubicando el ser humano en una escala de estatura promedio).

6. Huellas de uso o ruptura.

- Permiten diferenciar las armas de las herramientas, aunque son menos elocuentes en la distinción entre armas de guerra y armas de caza.

- Las hachas, cuchillos o puntas que servían a manera de herramientas domésticas pueden llevar huellas de uso.

- Los puñales y puntas de lanza utilizados para la caza o la guerra presentan ocasionalmente roturas a la altura del mango.

A continuación revisaremos las armas arrojadizas, aunque nos proponemos publicar ulteriormente el resultado de nuestras investigaciones referentes a las armas de choque.

\section{PROPULSOR O TIRADERA}

El propulsor es a menudo designado por su nombre mesoamericano: el atlatl, -ya que no hay nombre alguno en quechua ni en aymara-, o también estólica, quizás proveniente de los Indígenas Cuna de Nicaragua (Ravines 1990: 30); para otros autores, el origen de la palabra sigue siendo un enigma (Carrión Ordóñez 1997). Es un arma destinada a lanzar un venablo que puede ser de grandes dimensiones, hasta dos metros (Boas 1938: 243-244; Leroi-Gourhan 1973: 60; Testart 1985: 117-120; Rozoy 1992) ${ }^{1}$. En general, cuenta con un solo gancho en cuya parte distal se coloca el extremo posterior del venablo. El propulsor es fuertemente sujetado a la altura del hombro y, mediante un efecto de balanceo y de proyección, el venablo es propulsado horizontalmente hacia el blanco. Para que sea eficiente, se coloca un estabilizador sobre el venablo y se sujeta una punta de piedra o de hueso en la parte delantera. Según Otterbein (2004: 64-66) un venablo lanzado con la mano puede alcanzar una distancia de $25 \mathrm{~m}$ y hasta $100 \mathrm{~m}$ con un propulsor, pero su eficiencia se limita a un rango comprendido entre 45

1 Una revista trimestral le es ampliamente consagrada: "The Atlatl” theatlatl@gmail.com (The World Atlatl Association, Inc, Margie Takoch y el sitio siguiente publica una bibliografía anotada muy completa sobre el atlatl, http://web.grinnell.edu/anthropology/Atlatl de John Whittaker (2010), con más de 1000 entradas entre las cuales algunas se refieren al periodo prehispánico correspondiente a América del Sur. 
y 50 m. Según Testart (1985:120, nota 18) su alcance pasa de 20 a 30 m cuando es lanzado con la mano, y a 60-70 m cuando es lanzado con un propulsor. Es la primera arma compuesta inventada por el hombre, y se la encuentra en el mundo entero, excepto en el África y en la Antártica (Raymond 1986: 153). Su existencia es atestiguada en Eurasia desde el Paleolítico Inferior (Dennell 1997; Hoffecker 2005), pero sobre todo en el Paleolítico Superior (Solutrense), así como en el Nuevo Mundo, hacia el séptimo u octavo milenio a.C. (Lavallée 1995: 104; Otterbein 2004: 64). Otterbein añade que no se trata de un invento local, sino que habría más bien llegado desde Asia con la primera migración humana ${ }^{2}$. No obstante, parece haber caído en desuso muy rápidamente en Europa, frente al arco y las flechas, posiblemente durante el Mesolítico. Su descripción y su distribución en el área americana fue realizada por vez primera por Uhle (1907; 1909) y De Mortillet (1910), mientras que se encontraron numerosos especimenes provenientes del Arcaico chileno (Standen y Arriaza 2000: 243-244, Standen 2003: 175).

En la área centro-andina, las primeras estólicas nascas fueron muy rápidamente el objeto de estudio (Urteada 1920; Uhle 1907, 1909; De Mortillet 1910; Means 1920). El propulsor andino tiene la particularidad de contar con dos ganchos, el uno pequeño (tope), en la parte distal, para sujetar el venablo, y otro más grande (manija), en la parte proximal, sobre la cual el tirador colocaba el índice de manera a tener un buen punto de apoyo (Métraux [1949]1963: 244-45; Mayer 1998: fig. 3689-3699; 3741; 3723). Los ganchos pueden ser de piedra, concha (Fung Pineda 1969), hueso o metal (cobre, bronce arsénico, oro o plata). Estos dos ganchos se ven muy bien en los propulsores de madera cubierta de metal con ganchos de bronce en la tumba del Viejo Señor de Sipán (Fig. 1), o en las numerosas representaciones pintadas de guerreros Mochicas, entre las cuales figuran las dos vasijas de asa estribo -muy parecidasdel Museo Nacional de Antropología y Arqueología e Historia de Lima y del Museum für Völkerkunde de Berlín (Donnan y McClelland 1999: fig. 6.52 y 6. 53).

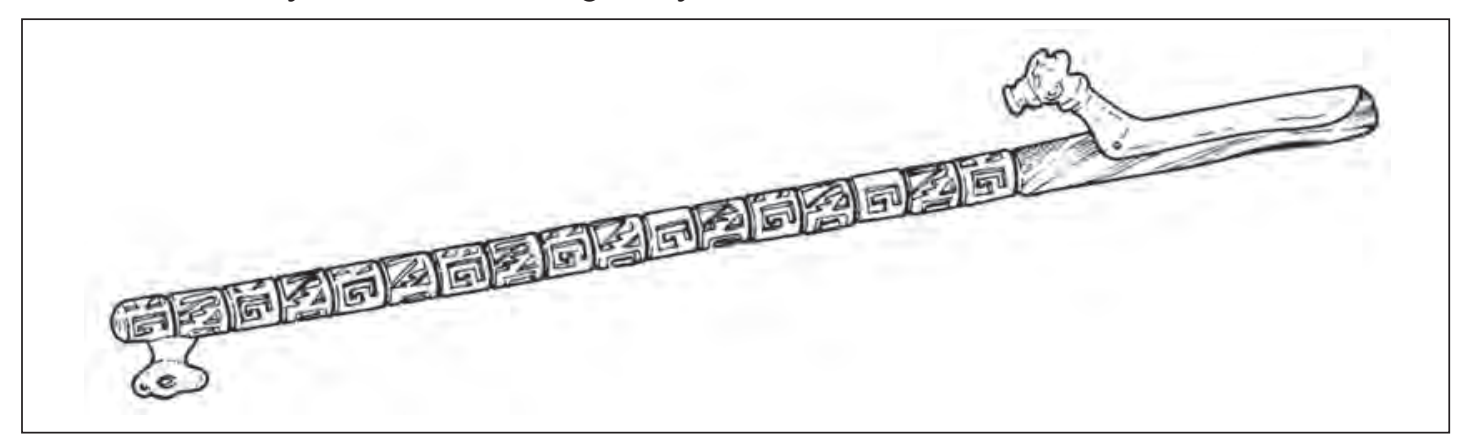

Figura 1. Propulsor antiguo, señor de Sipan, Alva 2007: fig. 273.

\section{Precerámico}

En las pinturas murales de Toquepala, varios cazadores sujetan objetos que son, quizás, venablos para propulsores, más aún tomando en cuenta que se puede ver en algunos algo parecido a plumas de estabilización (Ravines 1968: fig. 6, 7 y 9). En la sierra peruana, Hostnig (2003, 2007) descubrió miles de pinturas y grabados rupestres en la región de Macusani y Corani, al norte del lago Titicaca, que representan la vida de los cazadores de guanacos de la época de Toquepala. Hostnig es categórico: el arma de caza era la estólica, y el mazo servía para rematar al animal (Ibid. 2007: fig. 2); una escena en el sector de Oqhotera representaría un conflicto entre dos grupos de cazadores "armados con dardos, tipo cazadores portadardos", luego de la invasión del territorio de caza de un grupo por el otro (Fig. 2). Hostnig acota: "el dardo y la estólica, el mazo y quizás la lanza, deben haber conformado el arsenal de armas

2 Un venablo de propulsor de 10000 años de antigüedad acaba de ser identificado por Craig Lee con ocasión del deshielo de un glaciar del parque de Yellowstone en los Estados-Unidos (Sciencedaily june 30, 2010, Live Science 05 july 2010). 
empleado por los cazadores prehistóricos de la zona, que al parecer desconocían el uso del arco y la flecha".

En la costa del área centro-andina, su uso parece ser desconocido en el Precerámico antes de la fase 6 de Lanning (2500-1800 a.C.) ${ }^{3}$. Esta ausencia en la costa, cuando existía ya desde hacía mucho tiempo antes en la selva amazónica (Métraux 1963: 229), está sin duda ligada al hecho de que la subsistencia aquí era esencialmente marítima y hortícola. La caza terrestre debía desempeñar un papel muy débil, en tanto que la caza de mamíferos marinos en las playas se realizaba con mazos y no con hondas. Los propulsores más antiguos datan del Precerámico fase 6 de Lanning y fueron hallados en los sitios mencionados en la tabla 2.

\section{Periodo Inicial y Horizonte Temprano}

En el periodo Inicial y el Horizonte Temprano, se han encontrado muy pocos propulsores arqueológicos en los sitios de tradición Chavín, Cupisnique o Manchay (Tabla 3).

Tampoco se encuentran muchos propulsores en la iconografía. En una piedra grabada hallada por Mario Gonzáles en el campanario de la iglesia de Chavín en 1956 (Rowe 1962: 23 y fig. 17) ${ }^{4}$, se observa un dios alado sujetando una cabeza-trofeo en la mano derecha, y en

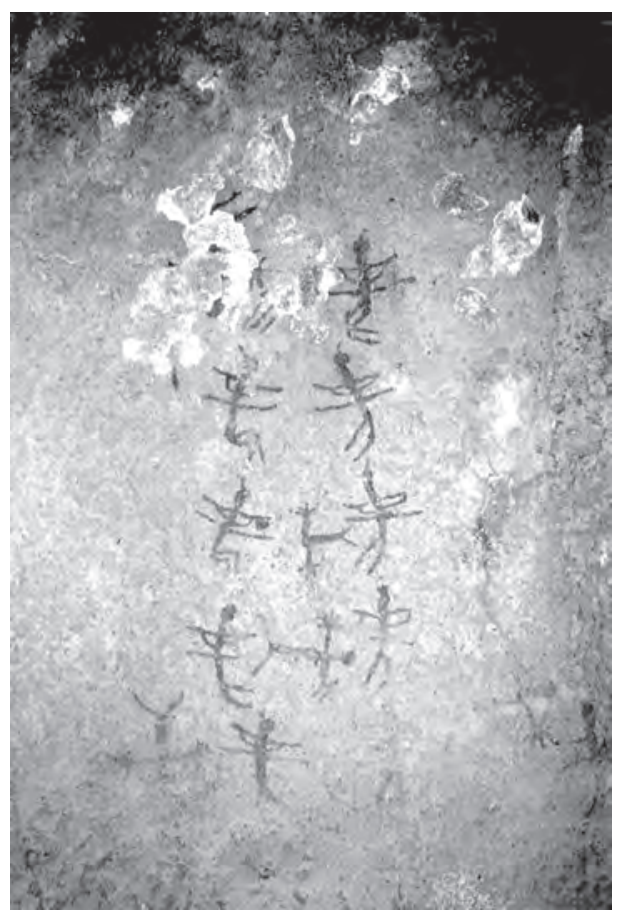

Figura 2. Abrigo rocoso de Oquhera (Macusani) guerreros con propulsores (Hostnig bulletin SIARD no 17, 2003) la izquierda, un propulsor junto a lo que parecen ser largos venablos. Los dos ganchos del propulsor se ven muy bien en este dibujo. Rowe (1974: 21 y fig. 4 b y c) ve aquí la primera representación de un guerrero que sin duda formaba parte de un desfile, tal como lo sugieren la fig. 4c y los comentarios de Roe "Llevan también [...] atlatls o venablos [...] esto data la primera aparición de guerreros así como del culto de cabezas-trofeo en Chavín". Lumbreras (1980: 264) comenta también este dibujo: "[...] la imagen más cercana de lo que puede ser un guerrero [...] Si se quiere, es posible proponer que esta representación implica la "caza" de cabezas, como parte de una institución que indudablemente es de tipo guerrero. El personaje está alado". En un fragmento de cornisa del muro oeste, encontrado en 2001 por Rick (2008: 21 y fig.1.15), uno de los tres personajes representados llevaría en la mano derecha una lanza, y en su mano izquierda, lo que parecería ser un propulsor. En Chavín nuevamente, Roe (2008: 212 y fig. 7.11) ha sugerido recientemente -según un análisis semiótico basado en una analogía etnológica con las creencias esotéricas de los Shipibo (la tribu amazónica más cercana de Chavín)-, que los personajes mitad rapaces, mitad jaguares de las columnas del Pórtico Blanco y Negro y de su hipotético lintel, así como aquellos del textil de Carhua (costa sur), llevarían más bien en sus manos propulsores y venablos en donde Rowe (1967: 84) veía mazos-espada (Ibid.: 87). Luego, en la fortaleza de Chanquillo, en la cuenca baja del río

3 Engel (1976: 83) revela haber encontrado un ejemplar en el abrigo rocoso de Tres Ventanas, en la cuenca alta del valle del río Chilca, fechado por el investigador en 7000 a.C., pero esta datación única debe ser puesta en tela de juicio. En la península de Paracas, en el sitio 104 también llamado Cabeza Larga u Osario, el autor nota -entre los 60 esqueletos-, la presencia de dardos, flechas o láminas finas de madera dura, así como báculos sólidos, pero, -según acota-, si bien la existencia del propulsor es posible, tampoco fue probada (Engel 1960, 1966a: 8).

4 El original se encuentra ahora en el nuevo museo de Chavín; 
Tabla 2: huellas de puntas de piedra pulida.

\begin{tabular}{|l|l|l|l|}
\hline \multicolumn{1}{|c|}{ SITIO } & VALLE & \multicolumn{1}{|c|}{ AUTOR } & CRONOLOGÍA \\
\hline $\begin{array}{l}\text { San Diego, Rosario, } \\
\text { Palka }\end{array}$ & Casma & S. y T. Pozorski 1987a: 60-62 70, 89 y fig. 40 & Fin HT \\
\hline varios & Nepeña & $\begin{array}{l}\text { Proulx 1985: 239-42 y lam. 10A y B; Daggett } \\
\text { 1984: 182-86 y fig. 5.23 y 5.25 y cuadros 5-1, } \\
\text { 6-1 y 6-2 }\end{array}$ & $\begin{array}{l}\text { Varias fases } \\
\text { del HT }\end{array}$ \\
\hline $\begin{array}{l}\text { Kotosh (ph. Chavín6 } \\
\text { Kotosh) }\end{array}$ & Huallaga & $\begin{array}{l}\text { Izumi y Sono 1963: 125 pl. 107-c, 167; } \\
\text { Izumi y Terada 1972: 249-250 y plate 52, 92 } \\
\text { y 156 }\end{array}$ & Fin del HT \\
\hline Huambacho & Nepeña & Shibata 2008 & Fin del HT \\
\hline Caylán & Nepeña & Chicoine e Ikehara 2008: 360 y fig. 17 & Fin del HT \\
\hline Chavín de Huántar & Conchucos & $\begin{array}{l}\text { Tello 1960: 311 } \\
\text { Muellée 1969-70: lam.10 } \\
\text { Sayre 2010: 152 y annexe J }\end{array}$ & Huaráz PIT \\
\hline Guitarero & Huaylas & Lynch 1980j & Huaráz PIT \\
\hline Huaricoto & Huaylas & Gero 1983 fig. 5; Burger 1985b y 2003a & Huaráz PIT \\
\hline Ticapampa & Huaylas & Muelle 1957, fig.15-20 & Huaráz PIT \\
\hline Huarijircon & Conchucos & Ravines 1970: 271-12 & Huaráz PIT \\
\hline Cerro Sechín & Casma & Muelle 1957, fig. 270 & Huaráz PIT \\
\hline Cuenca baja del valle & Santa & Muelle1957: fig. 30 y 31;MNAAH (Lima) & Huaráz PIT \\
\hline El Castillo & Santa & $\begin{array}{l}\text { Chapdelaine et al. 2002:22 y fig. 37; 2009: } \\
\text { 186 }\end{array}$ & Suchim. PIT \\
\hline Santiago de Chuco & Tablachaca & Pérez Calderón 1998 & Huaráz PIT \\
\hline Cerro de Arena & Moche & $\begin{array}{l}\text { Mujíca 1975: 312-52; Brennan 1978; } \\
\text { Lumbreras 1980: 271 }\end{array}$ & Salinar PIT \\
\hline Huaca Pedregal & Huarmey & Thomson 1964a: 543 & Baños de Boza \\
\hline Cuenca baja del valle & Chancay & Muelle 1957: 57 & Boza \\
\hline
\end{tabular}

Tabla 3. Huella de propulsores en el periodo Preceramico Algodón.

\begin{tabular}{|l|l|l|}
\hline SITIO & VALLE O REGIÓN & REFERENCIAS \\
\hline Otuma & Península de Paracas & Engel 1963a \\
\hline Asia & Costa sur & Engel 1957, 1963b :56 y fig. 132 \\
\hline Chira Villa & Costa central & Lanning 1967a : 68,: Cardenas Martin 1969 \\
\hline Los Chinos & Costa centro-norte, río Nepeña & Engel 1963a :18; 1963b : fig. 18 ${ }^{1}$ \\
\hline Culebras, Rio Seco & Costa centro-norte & $\begin{array}{l}\text { Engel 1958; Lanning 1967a : 68; Cardenas } \\
\text { Martin 1969 }\end{array}$ \\
\hline Áspero & Costa centro, río Supe & Burger 1992: 29 \\
\hline Telarmachay & Sierra de Junín & Lavallée 1985b : 247-50 \\
\hline
\end{tabular}

Casma, Ghezzi (2006: fig. 3.4 3.8 y 3.9) descubrió recientemente representaciones de propulsores en una decoración mural con fecha del final del Horizonte Temprano.

En conclusión, se puede afirmar que el uso del propulsor en el periodo Inicial y el Horizonte Temprano en las costas norte y centro-norte, si se dio, era restringido; parecía tener un valor simbólico y aparecía sobre todo en escenas ceremoniales. Si hubiese sido común, seguramente se habrían encon- 
trado muchos ejemplares, pues los ganchos de piedra o de hueso se conservan bien. Suponemos que la importancia de la caza había disminuido, debido al cambio de modo de subsistencia de este periodo, que presencia el pleno desarrollo de la agricultura irrigada, así como de la cría de camélidos y cuyes.

En la costa sur en cambio, en este mismo periodo, se encuentran numerosos propulsores en las tumbas de Paracas Cavernas (Tello y Xesspe 1979: 179 y fig.40.2; 233 fig. 68.5). En el Cerro Uhle (Ica), varios ejemplares completos de huesos de ballena con un gancho en "sperm whale tooth", grabados en forma de rostros humanos y parecidos a aquellos encontrados en Paracas, fueron también hallados en tumbas (Morris y Von Hagen 1993: fig. 37). Carrión Cachot (1949: fig. 5) ilustra cierta cantidad de ganchos de estólicas tallados en hueso, encontrados en las tumbas de Paracas (Fig. 3) o de estólicas enteras bordadas en mantos funerarios. Se acota asimismo la presencia de algunas representaciones de cazadores armados de propulsores en petroglifos fechados de este periodo, en particular en Chichictara, en el valle del río Palpa (Llanos Jacinto 2009: 97 y fig.11.4).

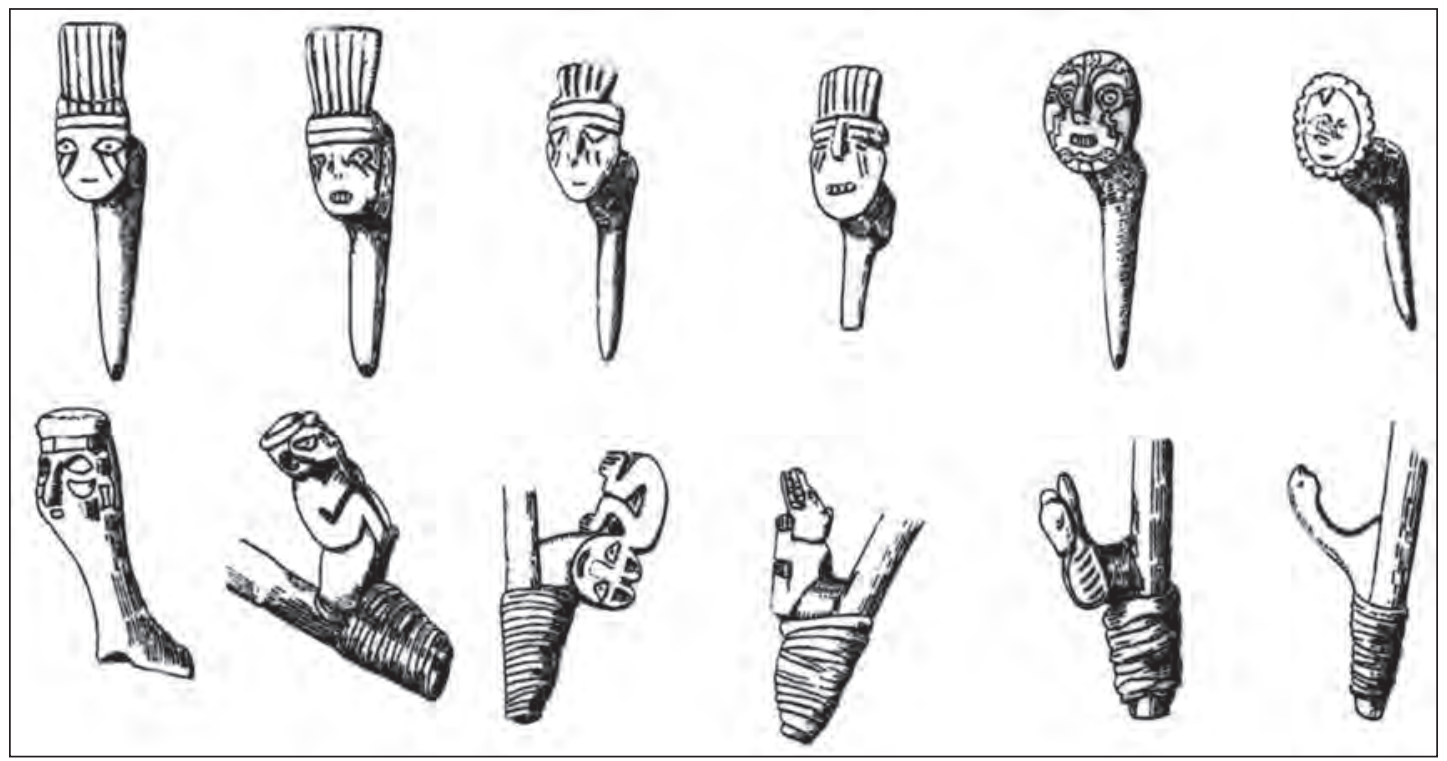

Figura 3. Paracas, gancho de estólica (Carrion Cachot 1949: fig.5).

\section{Periodo Intermedio Temprano}

Para el inicio del periodo Intermedio Temprano (fase Blanco sobre Rojo), en la costa norte y centronorte, no se han encontrado huellas de propulsores, ni en el registro arqueológico ni en la iconografía. Las excavaciones de Elera (1992; 1998) en Puémape y en Puerto Éten (fase Salinar) o de Brennan (1980; 1982) y Mujica (1975) en el sitio de Cerro Arena, así como las de las fases Layzón de Hucaloma y Layzón o de la fase Sotera de Kuntur Wasi y Cerro Blanco, no arrojaron ningún resto de propulsor.

En los valles de la costa central, en Nievería (Rímac), Uhle (1907: 120-21) ha encontrado y descrito tres propulsores con fecha del periodo Intermedio Temprano: uno de ellos tenía un cuerpo de madera: "Gancho hecho de concha colorada (Spondylus pictorum), de forma similar a la cabeza de un loro". Cinco otros propulsores encontrados ulteriormente en Nievería son citados por Uhle, de los cuales un espléndido ejemplar es detalladamente descrito (Ibid. 1909: lam. XXXVIII y XXXIX y fig.22). Willey y Corbett (1954) encontraron en Cerro Trinidad (Chancay) un atlatl de $22 \mathrm{~cm}$ de largo "tallado en hueso, la base es recta con una proyección en uno de sus extremos y preparado para sujetarlo al mango de la estólica [...] es del periodo Interlocking". Cárdenas Martin (1969) describe, en Nievería, una estólica de $54 \mathrm{~cm}$ de largo con un gancho en oso "un poco alargarda y acanalada para adaptar al palo. Representa la cabeza y cuello de un gato". 
Algunos propulsores aparecen en las tumbas Gallinazo, en particular en el valle del río Virú (sitio V-59 Strong y Evans 1952: 72 y lam. VII C y VII F; Larco 1945a: 15-16). Un mango de propulsor, con una protuberancia que hace oficio de primer gancho, así como una pieza que era sin duda el segundo gancho de madera dura de algarrobo, decorado con dos cabezas esculpidas de felinos, ha sido encontrado por separado en la tumba de un guerrero en donde un mazo de madera de cabeza bicónica también fue hallado. Finalmente, en la iconografía, en un geoglifo de la cuenca baja del río Santa, con fecha de la fase Suchimancillo (Gallinazo), uno de los dos humanos levanta lo que parece ser un propulsor (Wilson 1988: 797 y fig.2).

Los propulsores -generalmente con ganchos metálicos- se vuelven ya abundantes en la sociedad Vicús (Mayer 1998: fig. 3689-3699), y luego sobre todo entre los Mochicas, en donde el mango -en ciertos casos- está además cubierto de metal, tal como aquel encontrado en la tumba del Viejo Señor de Sipán (Fig. 1). Uhle atribuye al periodo chimú cuatro propulsores hallados durante sus excavaciones en las huacas del Sol y de la Luna (Uhle 1907: 122-126): tres al pie de la Huaca de la Luna sobre la plataforma "Uhle". Sin embargo, equiparamos la fecha de estos propulsores al periodo Mochica, al igual que otros artefactos de la plataforma Uhle hallados por Chauchat y su equipo. Larco Hoyle (tomo 1 2001:211-213) ofrece una descripción minuciosa de numerosas estólicas que pudo encontrar en los diferentes valles del Centro-Norte. Desde aquel entonces, los arqueólogos han encontrado muy bellos ejemplares en las tumbas de la élite mochica recientemente descubiertas: Sipán (Alva y Donnan 1993: fig. 188; Alva 2001, 2007), Dos Cabezas (Donnan 2003) y sobre todo, El Brujo, en donde se han encontrado -asociados a la "Dama de Cao"-, veintitrés estólicas en buen estado, con ganchos de metal dorado sobre los cuales aparecen representaciones de figuras antropomorfas o aves (Franco 2009) y otras dentro de una tumba removida encima del edificio; éstas corresponden únicamente al mango de madera tallada con "animales lunares" con incrustaciones de conchas y crisocola (Franco, Gálvez y Vásquez 2001: 142, foto 25).

No obstante, en la época de los Mochicas, no se trataba -al parecer- de un arma de guerra, sino más bien de caza, pues casi nunca se la encuentra en la iconografía guerrera, mientras que casi siempre aparece en las escenas de caza de venado, asociada al empleo de redes tendidas entre dos estacas, tal como se lo puede ver en las numerosas escenas de caza reproducidas por Kutscher (1983: fig. 68-86) y Donnan y McClelland (1999, fig. 4.88) (Fig. 4). En el corpus de las varias miles de representaciones que hemos consultado, existen guerreros equipados con estólica, pero en cantidades muy escasas: (McClelland 1999: fig. 4.105, 6.52 y 6.53; Lumbreras 1980: lam. 364). A la inversa, se encuentran muy pocos ejemplares de caza de venado con porras (Kutscher 1983: fig. 87; Donnan y McClelland 1999: fig. 6.85-6.88).

Esta especialización de armas entre los Mochicas ha sido asimismo notada por Verano (2001: 112113) y Bischof (2005: 77). Con el fin de demostrar que la caza es una actividad ritual, Donnan (1978: 266) compara un combate entre humanos en donde los guerreros están armados de porras y llevan la chalchalch ${ }^{5}$ colgada de la cintura, a una caza de ante en donde los cazadores están armados de propulsores, y no llevan la chalchalcha (Ibid: fig. 265). Otra prueba según la cual el propulsor no es de uso guerrero, es su empleo en escenas de juegos rituales pintadas en varias vasijas comentadas por Kutscher (1958). En una escena de presentación de la vasija de sacrificio (Ibid. fig. 2; 1983, fig. 150), los personajes llevan a la vez un propulsor y lo que Donnan llama un "báculo de piezas cruzadas", del cual un ejemplar ha sido hallado intacto en una tumba (Donnan y McCLleland 1978: fig. 115, 116). Ahora bien: estos báculos -de los cuales cuelga una soga terminada por un "pétalo o volante"- se encuentran entre las manos de personajes a punto de lanzarlos mediante un propulsor (Kutscher 1958, fig. 1). En una botella asa de estribo Moche V (Ibid.: fig. 113), los dos personajes de la izquierda llevan báculos de este tipo, mientras que los demás personajes levantan propulsores. En otra vasija (Fig. 5, Kutscher 


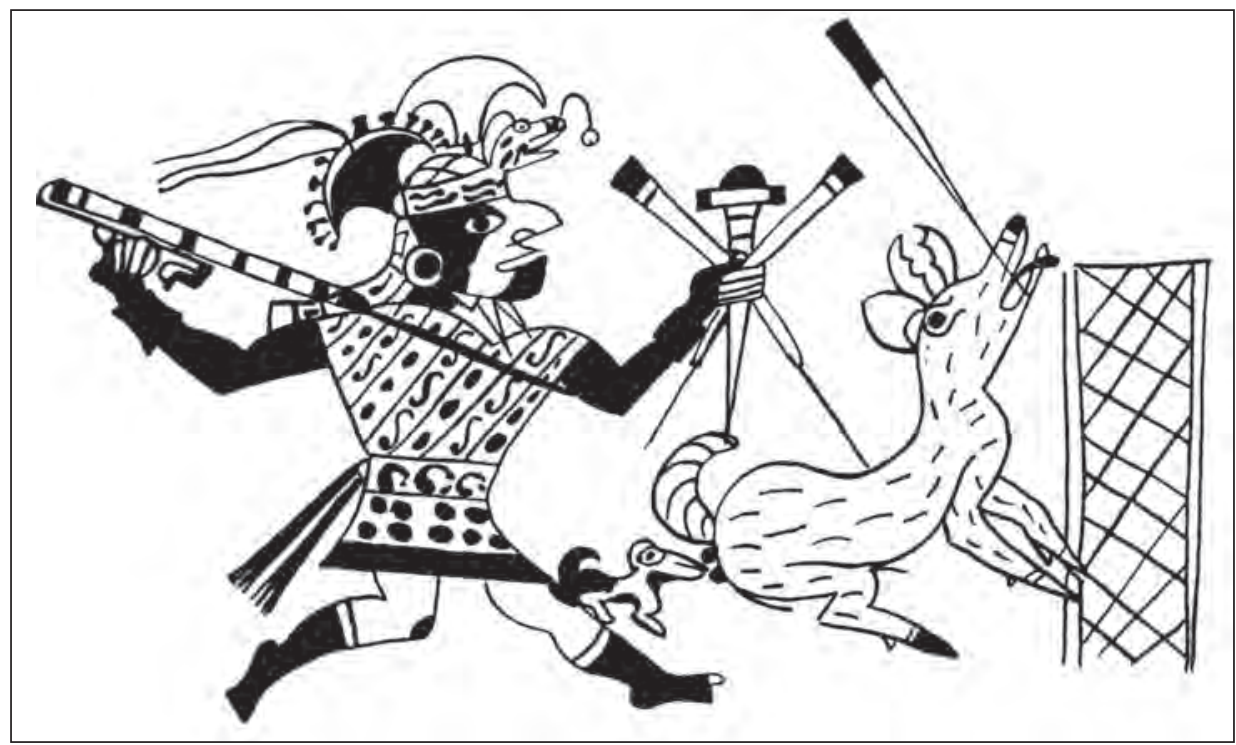

Figura 4. Moche IV. Caza de venado con propulsor. Donnan \& McClelland 1999: fig. 6.82.

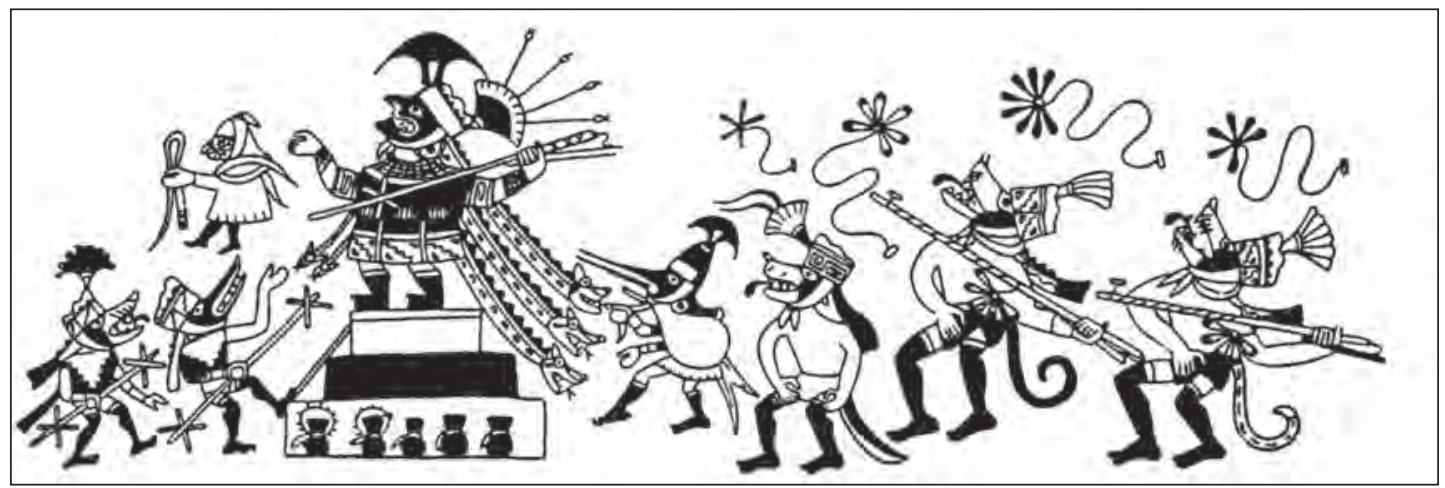

Figura 5. Badmington ritual (según Kutscner 1958: fig. 3).

1958, fig. 3), algunos personajes antropomorfos llevan a la mano este báculo de piezas cruzadas, mientras que otros se preparan a lanzar un venablo sin punta, y que alrededor de ellos, vuelan "pétalos o volantes" en suspensión, atados a la punta de una soga en cuyo extremo se encuentra una clavija. Según Kutscher (1958) y Hocquenghem (1979), estos báculos de piezas cruzadas serían utilizados en un juego ritual al que llaman badminton, durante el cual "pétalos de flores" (Bourget 2006) o "volantes" (Kutscher 1958) serían lanzados, a veces emparejados a la escena de la presentación. No obstante, los celebrantes no son guerreros, pues ninguno lleva la chalchalcha característica del atuendo de los guerreros mochicas.

Entre los vecinos y contemporáneos de la sierra, los Recuay, valga recalcar que no consta ni un solo ejemplo (arqueológico o iconográfico) de propulsor.

Se encuentran propulsores entre los Lima, pero dos ejemplares hallados en Nievería sólo tenían el gancho distal, al igual que aquellos identificados en la Amazonía (Métraux 1963: 246).

En el sur, la tradición Nasca perpetúa la tradición Paracas, mientras que se siguen encontrando propulsores de dos ganchos en grandes cantidades, muy similares a aquellos de Paracas Cavernas (Silverman y Proulx 2002: 157-160), tanto en las tumbas como en la iconografía (Lavalle 1989: fig. 125; 
Proulx 2006), y mantos funerarios de Necrópolis (Tello y Xesspe 1979: 336 fig. 91): ver por ejemplo el borde del manto del fardo 451 de Cerro Colorado, en el cual todos los personajes fantásticos sujetan con la mano la cola de un mono, el cual a su vez lleva una estólica (Tello [1959] 2005: lam. XXXV à XLI), o también los personajes que llevan una estólica en la una mano, y venablos en la otra. En el fardo 249, una de las figuras pintadas en tela, lleva dos propulsores en una mano, y venablos en la otra. Se los puede encontrar acompañados por sus respectivos venablos, como en las tumbas de Cahuachi (Orefici 1993: fig. 168; Kroeber y Collier 1998: 51, 79-80). Proulx menciona de 8 a 10 venablos -asociados a una estólica- encontrados en la tumba 61 de Cahuachi: "Propulsores, o atlatl, han sido encontrados en numerosas tumbas Nasca; también son hechos de madera de huarango, con ganchos de metal o hueso, a menudo con la forma de pájaros o animales. Estos propulsores suelen verse en manos de guerreros pintados en la cerámica tardía, a menudo con loros colocados aquí por algún motivo simbólico" (Proulx 2001:127). Mayer (1998: fig. 3693 foto $n^{\circ} 1$ ) reproduce un propulsor y su pequeño gancho de cobre, encontrados junto a una pieza de cerámica Nasca en una tumba cerca de Callango (Ica, Nasca III), cuyo origen dice ignorar. Sin embargo, nosotros sí pudimos encontrarlo en una ponencia presentada en el $32^{\circ}$ Congreso de Americanistas, en Copenhague (Feriz 1958). Se trata de una pieza espléndida encontrada cerca de una momia y de una vasija Nasca III en Callango, cuyo gancho proximal (maneja) de cobre representa un pájaro sujetando una bola en el pico, mientras que el gancho distal (tope), esculpido en marfil, representa la cabeza de una serpiente. Siendo el cobre escaso en la costa sur, el autor postula que el gancho viene de la costa norte (Mochica). También cerca de Callango, cerca del esqueleto decapitado de un hombre joven, DeLeonardis (2000: 371) encontró dos propulsores sin sus ganchos ${ }^{6}$. En Acarí, en la tumba de dos niños varones, Lothrop (y Maller 1957: 6, 42, 43 y lam. XIX y XX) ha encontrado tres de ellos hechos de madera de chonta, de las últimas fases de Nasca.

Pero, al igual que entre los Mochicas, las estólicas y los venablos con puntas de obsidiana, cuyas representaciones conocidas son numerosas, servían aquí esencialmente para la caza, (Donnan 1992: fig. 93; Eisleb 1977: 207; Kroeber y Collier 1998: fig. 259, 272); ver en especial una vasija del Museo Amano que representa al cazador, con la estólica armada en su brazo doblado, apuntando llamas (Proulx 2006: fig. 5.262). A la inversa, nunca se encuentran representaciones de guerreros en combate levantando la estólica; quizás los guerreros mencionados por Proulx en la cita anterior sean en realidad cazadores.

\section{Horizonte Medio}

Se puede citar un propulsor encontrado en Ancón con fecha del Horizonte Medio, así como una serie de 18 propulsores, en madera de chonta o de hueso, en muy buen estado, hallados en una tumba en Chaviña (Uhle, 1909: lam. XXXVIII, XXXIX). Éste postula la interesante hipótesis de su uso en calidad de arpón para la pesca, pues los ha encontrado en una tumba ubicada a orillas del mar, mientras que ninguno ha sido hallado en las tumbas localizadas tierra adentro; en cambio, junto a estos propulsores, ha encontrado venablos dentados; supone que el cabo de algodón que unía el arpón al propulsor estaba fijado en el gancho proximal de este propulsor. Una vez más, no se trataba pues de armas de guerra. En el lejano Altiplano, varios autores sugieren que la figura central de la puerta del sol en Tiahuanaco levanta una estólica en la mano derecha (Uhle 1907: 123 nota 1; Métraux 1963: 244-45; Bushnell 1965: 93-94; Bankes 1977: 1447; Bischof: 2005: 74); Mirando a la Fig. 6, este punto nos parece indiscutible. Dos representaciones más del "Dios de los báculos", casi idénticas entre sí, se encuentran, la una en la estela 8 o Monolito de Ponce (Isbell y Knobloch 2006: fig.12.2) y la otra, en un fragmento de cerámica encontrado en Conchopata en 1977 (Ibid.: fig. 12.5). En los dos casos, el personaje central de

6 Llanos Jacinto (2009: 244) dice que se trata de lanzas cuyas puntas habían sido retiradas. Estudiando atentamente la figura 6 de DeLeonardis 2000, pensamos que se trata efectivamente de propulsores.

7 "El [báculo] que está en la mano derecha es probablemente un propulsor y tiene una cabeza de águila en la parte superior para representar el gancho". 

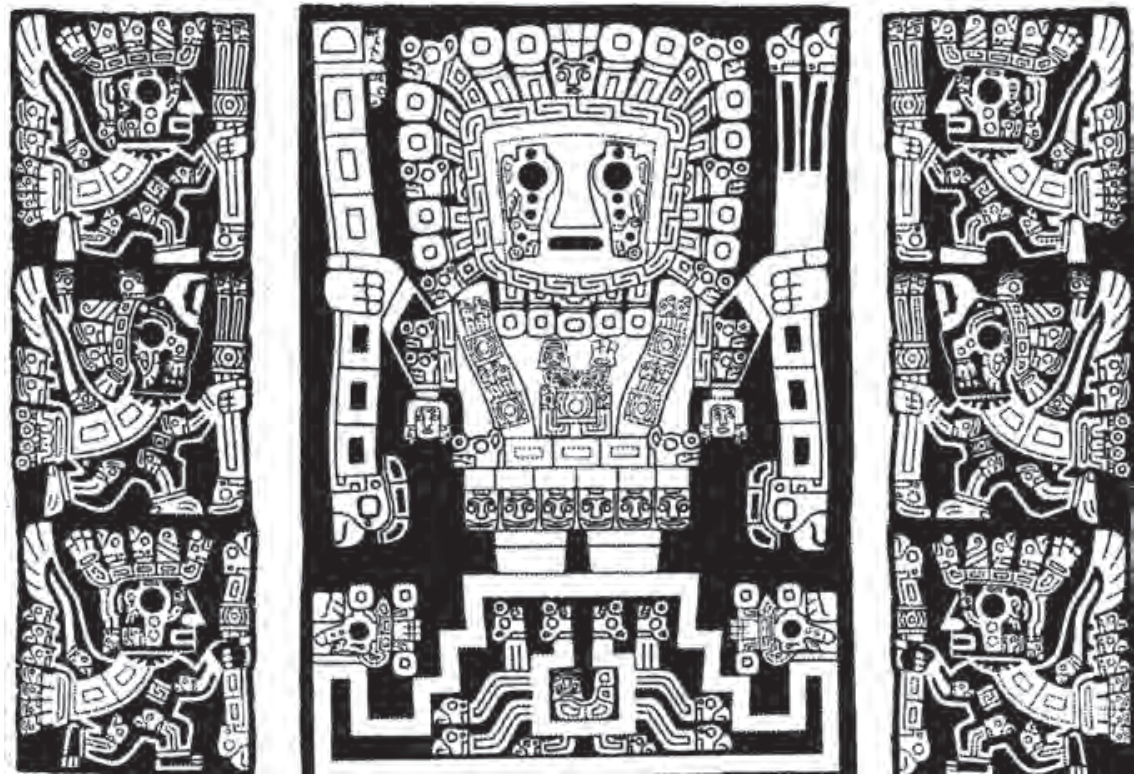

Figura 6. Tiahuanco. Portada del sol, según Llanos 2009: fig. 12.2, según diseño de Miller 1996.

cabeza "radiante", sujeta en la mano derecha una estólica, y en la izquierda, un cetro terminado en una cabeza de felino, en tanto que los personajes circundantes sólo llevan báculos en forma de serpiente, lo cual parece subrayar la importancia otorgada a la estólica del personaje principal. Más lejos todavía, en Pacheco, cerca de Nasca, dos personajes (un hombre y una mujer) están representados en la misma postura en una urna gigante (Morris y Von Hagen 1993: 113, 121 y fig. 101 y 102; Isbell y Knobloch 2006: 307); el hombre lleva lo que parece ser una estólica en cada mano, mientras que la mujer sujeta lo que parece ser una planta terminada en una cabeza haciendo muecas. Fuera de esta referencia, no encuentro sino el ejemplo dado por Tung et al. (2007: 223) de un guerrero de Conchopata quien llevaría en la mano derecha aquello que los autores llaman una estólica en la leyenda del dibujo, y en el texto, "Una especie de lanza o estólica", pero que se parece mucho más a un mazo de cabeza redonda y extremidad proximal en forma de punta. Es no obstante preciso acotar que Isbell y Knobloch (Ibid.: 324-340), así como Makowski (2001), quienes analizan las diversas representaciones de "dioses de los báculos" y su evolución en Pucara, Conchopata/Huari y Tiwanaku, nunca sugieren que se trata de una estólica. El debate sigue abierto.

\section{Intermedio Tardío y Horizonte Tardío}

El propulsor parece desaparecer luego del armamento en el periodo Intermedio Tardío, al menos de lo que se sabe hasta la fecha.

Su presencia entre los incas es motivo de controversia. Francisco de Jerez (1534) dice que, durante la fiesta del Inti Raymi en la gran plaza del Cusco, algunos capitanes llevaban una estólica a manera de arma nacional (Uhle 1907: 123). Por lo demás, Uhle escribe la página siguiente: "no quiero negar que es probable que la estólica se hubiese usado en algunas partes del Perú al tiempo de la conquista; pero es cosa inverosímil y no probada que esta arma hubiese estado en tan común uso durante los últimos siglos. Aceptando la teoría de que en el Perú el uso de la estólica era más común en los períodos primordiales que en los que les sucedieron, encontramos en uso una nueva prueba que la estólica es una arma primitiva del hombre,

8 El subrayado es mío. 
más primitiva que el arco, y que por eso suele caer en desuso en todas partes antes que este último." (Ibid.: 124). El autor piensa que su uso era poco común en el Tahuantinsuyu. y sugiere que se encontraba solamente con las tropas originarias del Ecuador, "en donde la estólica aún era de uso común hasta los tiempos de la conquista"(Ibid:: 123-124). De hecho, su nombre en quechua no ha sido registrado por los cronistas, quienes lo llamaban "amiento de palo", recordando el "amentum" romano (Garcilaso de la Vega). Urteaga (1920) anota que durante la fiesta del "Raymi", en la gran plaza del Cusco había simulacros de combates con la estólica, y que ésta subsiste únicamente en calidad de "símbolos en el ceremonial políticoreligioso" (Urteaga 1928: 117). Según Bischof (2005: 74), se halla prácticamente ausente del ejercito, y no es utilizado más allá de su calidad simbólica en el ceremonial político-religioso. Quiroga Ibarrola (1958: 388) quien hace el listado de todos los cuerpos de guardia del ejército inca, no cita las tiraderas, y se puede suponer que el propulsor había sido ampliamente remplazado por el arco. Ravines (1990: 32) dice que formaba parte del armamento guerrero de los Incas, pero las numerosas citas de cronistas a las que alude se refieren a combates y hechos de armas ubicados en el Ecuador o extremo norte del Perú (en particular los combates de Tumbes y las islas), lo cual confirmaría que se trata de una tradición de esta región del Tahuantinsuyu. Se puede luego concluir que su existencia está ligada a las conquistas del Ecuador.

\section{Azagaya y Venablo (THROWIng SPEAR)}

Se trata del arma arrojadiza lanzada ya sea directamente con la mano (azagaya), ya sea por medio de un propulsor (venablo), y es imposible saber de cuál de ellas se trata cuando se las encuentra en tumbas y en la iconografía, a no ser que esté representada al mismo tiempo que el propulsor, tal como en la estela Chavín mencionada arriba, así como en los dos trozos de cornisa de la pared oeste de Chavín, recientemente descubierta por Rick (2008: 20, fig. 1.15), en donde los tres personajes sujetan en la mano derecha un venablo, mientras que uno de ellos lleva lo que parece ser un propulsor

Las azagayas armadas de puntas Paiján (8000 a.C.) eran probablemente usadas como armazón de arpón (Chauchat 1992) o para la caza de venados de cola blanca o venado de Virginia, Odocoileus virginianus (Gálvez y Quiroz 2008). Algunas puntas de obsidiana del Precerámico Final, tal como aquellas encontradas en Chilca (Engel 1988: 19) o en Asia (Engel 1963b), podrían haber sido armazones de azagayas o venablos, esencialmente utilizados en la caza de animales de tamaño mediano tales como los venados y los camélidos salvajes de montaña.

En el uso de los propulsores, vimos que se encuentran numerosas puntas de obsidiana en las tumbas de Paracas Cavernas fechadas del final del Horizonte Temprano, probablemente utilizadas como puntas de azagaya o de venablo. Algunas presentan huellas de sogas de algodón enrolladas, posiblemente destinadas a halar el venablo hacia sí cuando éste no había alcanzado su objetivo, o para sacar al pez, en el caso de ser usado como arpón (Uhle 1909).

Según Proulx (2006: 172), en la tumba 61 de Canas (Intermedio Temprano) en el valle de Nasca, Farabee ha encontrado ocho a diez venablos con sus respectivas puntas de obsidiana junto a un propulsor, mientras que Kroeber ha hallado fragmentos en las tumbas 10, 12 y 13 de Cahuachi. Cárdenas Martin (1969) menciona un asta de venablo de madera con un mango de hueso finamente trabajado, encontrada en la zona de Nasca: "Aquello representa una figura mítica tallada en el estilo grandilocuente de Tiahuanaco, con ojos fantásticos, incrustada con turquesas que, con sus órbitas redondas, mira el más allá [...] arma ceremonial [...] $58.5 \mathrm{~cm}$ de largo [...] mango sujetado al aspa por cuerdecillas cubiertas por una especie de resina. Colección Norbert Mayrock".

El venablo es representado en la iconografía de todos los periodos. Aparece frecuentemente en varios ejemplares en la iconografía Nasca, en donde los personajes míticos y los guerreros llevan varios de ellos en la mano, a veces atados entre sí (Proulx 2006: 172 y fig. 5.253, 5.257). Tello (1959): fig.113118) reproduce numerosos venablos que acompañan a los propulsores entre las manos de los cazado- 
res; se ve muy claramente en los dibujos la punta negra de la obsidiana que los equipa (Ibid.: 250). En fin, en ciertas representaciones de sacrificios, aparece un instrumento de madera de huarango sujetado en una mano, abombado en su parte central, junto a lo que parece ser un estabilizador en la parte posterior (Fig. 7); Proulx (2006, fig. 5.124 5.253) lo llama "spear or dart" (venablo) y Llanos Jacinto (2009: 250), quien lo califica simplemente de "arma" lo ha encontrado en Cahuachi tanto en textiles (Ibid. fig. 11.52a) como en vasijas (Ibid. fig. 11.52b (A y B). Encontró además un ejemplar arqueológico (Ibid. fig. 11.52 b (C) en una de las plataformas de Cahuachi.

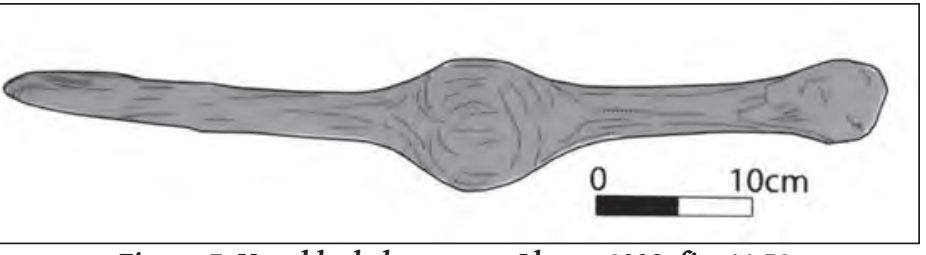

Figura 7. Venablo de huarango. Llanos 2009: fig. 11.52.

De acuerdo a Means (1931: 65-66), quien interpreta el extracto de Las Casas anteriormente citado, se trataba del arma predilecta en la costa durante un periodo anterior a los incas "the people of the coasts, during this early period, used javelins in their wars, whereas the contemporary highlanders used slings as their chief weapon of offense".

Lo cierto es que casi nunca se ha encontrado punta de venablo o de azagaya alguna en los esqueletos de los numerosos entierros, indistintamente del periodo, mientras que las huellas de traumatismos atribuidos a armas de choque son numerosas. Conocemos dos excepciones: una punta de flecha dentro del músculo del brazo de un varón de Paracas Necrópolis (Engel 1966, fig. 69) y otra incrustada dentro de una vértebra de un hombre en Huancalevica fechada del final de Nasca (Ravines 1967). Podemos también mencionar las puntas incrustadas en los huesos de entierros en Pacatnamú correspondiente a una probable matanza (Donnan y Cook 1986 vol. 1).

\section{Puntas De PIEDRA TAllada o hueso}

La presencia de puntas de piedra tallada, -a menudo de obsidiana-, asociada a redes de intercambio a larga distancia (Burger y Glascok: 2009), es frecuentemente aludida por aquellos autores quienes defienden la presencia de la guerra en el periodo Arcaico (Aldenderfer 2005: 20, 29), aunque éste reconoce que no encontró ninguna huella de estas puntas (ni tampoco de traumatismo alguno) en las numerosas sepulturas que excavó y estudió en los sitios de sierra cercanos al lago Titicaca (Ibid.: 24). Sin embargo, el hecho siguiente -sumamente significativo por cierto-, amerita precisamente ser subrayado: como lo vimos más arriba, en toda el área centro-andina, no se ha encontrado ningún ejemplo de puntas de piedra, talladas o pulidas, clavadas en los esqueletos o cerca a ellos (salvo las dos excepciones citadas más arriba). A la inversa, entre los Chinchorros (5000-1500 a.C.) del sur de Perú y norte de Chile, se conocen varios ejemplos de puntas de piedras clavadas en cuerpos: en Villa del Mar, cerca de Ilo, seis puntas estaban clavadas en el cuerpo de una mujer de 17 a 20 años de edad (Guillén y Carpio 1999), mientras que en Chile, una punta de piedra ha sido encontrada, clavada en la columna vertebral de un individuo (Arriaza et al. 2008: 48 y fig. 3.3). En Europa (Guilaine y Zammit 1998: 193202; Pearson 2005: 26 y nota 5) así como en América del Norte (Otterbein 2004, Lambert 2007), desde el famoso hombre de Kennewick (Haas 2001: 335), en cuyo esqueleto se encontró una punta de flecha, los ejemplos abundan (Cordier 1990). Tenemos pues la prueba que los propulsores y azagayas eran usados como armas de caza y no de guerra en la área centro-andina.

\section{Precerámico}

Tan antiguas como el hombre, las puntas de piedra tallada llegaron con él a los Andes. Lo más probable es que hayan sido utilizadas como herramienta y arma de caza a la vez entre los cazadoresrecolectores. En función de sus dimensiones, podría ser un armazón de lanza, de venablo lanzado 
con propulsor o de azagaya lanzada con la mano, de flecha lanzada por un arco, cuchillo o puñal, o también, un instrumento de trepanación. La historia de su evolución morfológica estaría aquí fuera de nuestro propósito, pero es útil constatar que las bellas puntas talladas de tipo "cola de pescado", de tipo "Paiján" o puntas foliáceas un poco más tardías halladas en Lauricocha (Cardich 1958; 1964), Pikimachay (MacNeish et al. 1980: 42; 78-94) así como en bastantes otros lugares de los Andes, desaparecieron progresivamente de la parafernalia del hombre andino de la costa norte al final del periodo Arcaico, poco tiempo después de la extinción de la megafauna pleistocénica, sin duda debido al cambio en el modo de subsistencia (M. Cohen 1978).

En la costa central, la tradición de las bellas puntas talladas de obsidiana o de cuarcita (Fig. 8) ha perdurado por mucho más tiempo, por ejemplo en los sitios del Precerámico Final de Chira Villa (Lanning 1967: 78), Chilca (Engel 1988), Asia (Engel 1963b) y Río Seco (Wendt 1964, fig. 19, 20). Podría tratarse de armazones de venablos lanzados mediante propulsores encontrados en el mismo sitio, más aún a sabiendas de que, en Asia, según el autor, había también restos de una aljaba de caña y algodón (Engel 1963b: 56 y fig.133-135). En este caso, se trataría probablemente de caza de animales pequeños o de aves.

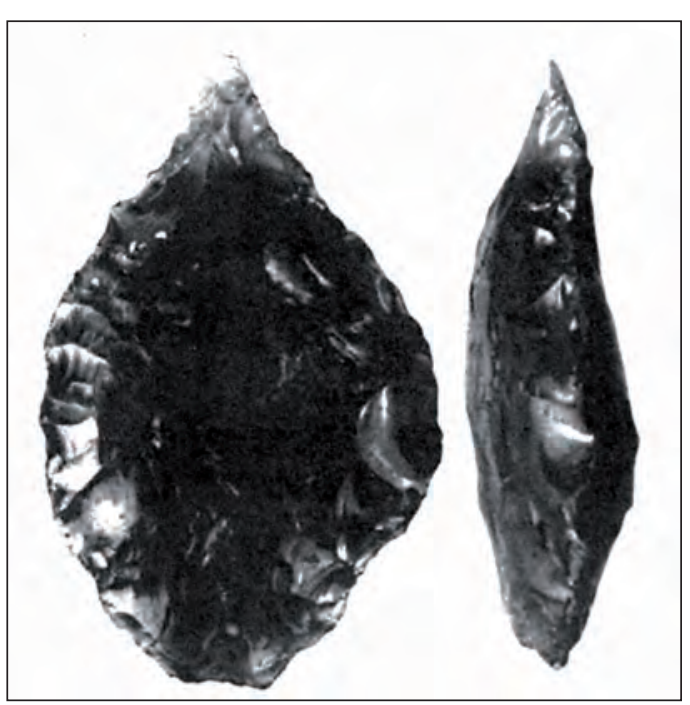

Figura 8. Asia. Punta de obsidiana. Engel 1963: fig. 35.

\section{Periodo Inicial y Horizonte Temprano}

Subsistieron más tiempo en la sierra (tanto peruana como boliviana, argentina o chilena), así como en la costa sur, hasta el final del Horizonte Temprano al menos, seguramente a causa de la persistencia de la caza de venados y camélidos (Dillehay, Bonavia y Kaulicke 2004: 20, 21; Klink y Aldenderfer 2005: 52-53; Tripcevich 2006). La forma que perduró en la costa norte es mucho más rudimentaria (Engel 1972: 115). La caza se volvió secundaria, en tanto que la fauna incluía en aquel entonces animales de tamaños mucho menores (vizcachas, zorros del desierto y venados pequeños), para los cuales otros tipos de armas son más adecuados, en particular la honda, que aparece precisamente en el Precerámico Final. Las herramientas de piedra tallada pasaron luego a la esfera de los quehaceres domésticos, el despedazamiento y faena de pieles, pero no requerían la bella forma funcional de las puntas foliáceas o Paiján. Es luego interesante observar que la evolución de los medios de subsistencia -y no el uso guerrero- hace evolucionar la forma y las dimensiones de las puntas (Dillehay 2000: 220).

Tal como se vio más arriba, en la sierra, la necesidad de estos implementos siguió vigente, pues la caza de venados y camélidos permaneció pero, contrariamente a la costa, las mismas puntas bifaciales triangulares o foliáceas podían servir tanto para la caza como para la faena de pieles o el despedazamiento de las mismas, así como lo demostraron las huellas de uso disimétricas en las puntas de los niveles formativos de la cueva de Telarmachay en la región de Junín (Lavallée 1977). Se observa el mismo fenómeno en la fase IV de Lauricocha en el Alto Marañón (Cardich 1964: 70 fig. 53-54), así como en el Callejón de Huaylas (Lynch 1980). En los sitios de Ilave (río de la costa sur del lago Titicaca), y en la cuenca alta del río Colca, se encuentran puntas de todos los tamaños, incluyendo puntas diminutas de obsidiana de tipo 5d (largo comprendido entre 16 y $26 \mathrm{~mm}$ siguiendo la clasificación de Klink y Aldenderfer 2005), que habrían podido servir como armazones de flechas, desde el Precerámico hasta el Horizonte Tardío (Ibid.) 
Las puntas de obsidiana del sitio Hacha, río Acarí (Riddell y Valdez 1988: 7 y fig. 2, Valdez 2000: 20) se encuentran en la costa sur, durante el periodo Inicial. Estos autores opinan que servían para la caza de guanacos, pues han sido encontradas cerca de restos de camélidos así como de representaciones de camélidos sobre rocas (Valdez 2000, fig. 2). No obstante, la mayor cantidad de estas puntas (de diferentes tamaños), se encuentra en esta misma costa, en el Horizonte Antiguo. En Paracas, bellas puntas de obsidiana de bordes retocados (Fig. 9), encontradas en las tumbas, debieron servir como armazones de venablos lanzados mediante propulsores o para las lanzas que también se hallan presentes en las tumbas (Tello y Xesspe 1979: fig. 20, 39, 68); de hecho, según Xesspe y Carrión Cachot, se trata de un instrumento de trepanación. Carrión Cachot (1949: lam. XXIV) habla de cuchillos o de puñales, aunque el mango, roto en el punto de enganche, no permite clasificarlas dentro de una categoría específica. En la cuenca media de Callango, en el sitio de Ánimas Altas, hacia el año 100 a.C. sin cal., así como en otros sitios de la cuenca baja del río Ica, Menzel (1971: 83) da cuenta de la presencia de centenares de grandes puntas de proyectil de ob-
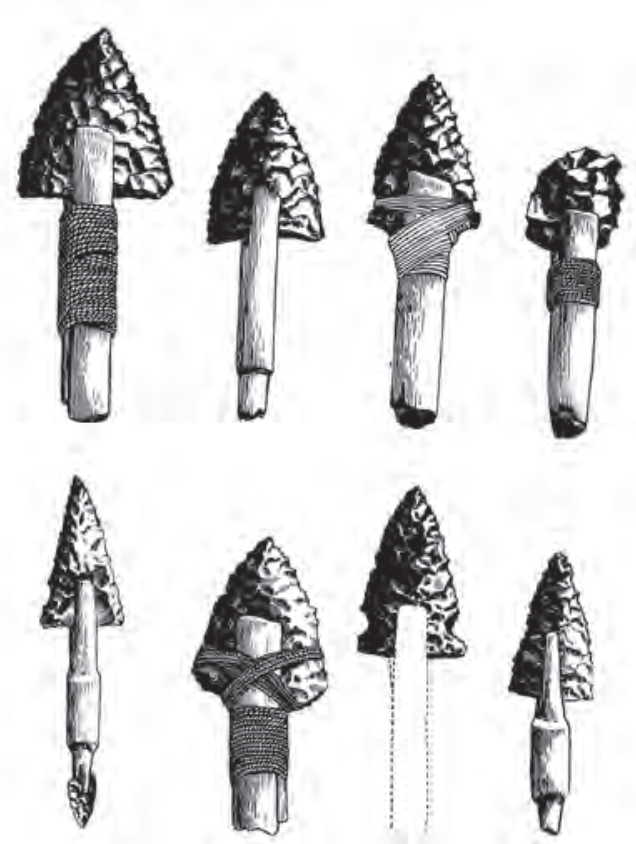

Figura 9. Sistema de enganche puntas talladas. Paracas. Carrion Cachot 1949: pl XXIX.

sidiana, de las cuales varias tenían la punta rota, lo cual demuestra que habían sido utilizadas. Otras puntas vienen de un sitio coetáneo al de Casa Vieja, a cinco kilómetros de Ánimas Altas (Massey 1986: 299 y fig. 7.6). En Cahuachi, durante la fase Nasca (tumba 6), se encontraron 8 a 10 puntas de piedra talladas a manera de armazones de venablos lanzados con propulsores (Proulx 2001: 127).

\section{Puntas de piedra pulida}

Las clasificamos aquí de acuerdo a su definición morfológica. Desde luego, cuando es posible, los arqueólogos les atribuyen naturalmente un uso: puntas de proyectil, de lanza o venablo, puñal o hacha (Muelle 1957; Lavallée 1969-1970; Lumbreras 1980; Brennan 1978: 321).

Cuando la punta es utilizada como arma, se trata de un arma ofensiva penetrante, puñal o cuchillo cuando no tiene mango o está conformada por un mango corto, y armazón de flecha, venablo, lanza o pica si está ensamblada sobre un asta. Pero puede también dividirse en armas de retención o armas arrojadizas, de acuerdo a las dimensiones de la punta, pues en el caso de un arma arrojadiza (punta de flecha, o de venablo), el arma debe ser lo más puntiaguda y liviana posible, de manera a conservar una fuerza de penetración suficiente desde cierta distancia, mientras que para ser usada a manera de puñal o de pica, podía ser más pesada (Fig. 10) (Lavallée 1970: fig. 10).

Aparecieron en Kotosh en la fase Kotosh-Chavín (8 ex.) pero más aún a la fase Sajara-Patac contemporánea del Intermedio Temprano (17 ex.) (Izumi y Sona 1960: 117 lam. 107; Izumi y Tereda 1972: 249-250 y lam. 52, 92 y 156), es decir, según la evidencia arqueológica, de forma muy tardía en los Andes, posiblemente en el final del Horizonte Temprano, y con mayor certeza al inicio del periodo Intermedio Temprano, momento a partir del cual se vuelven rápidamente muy numerosas. El uso de la piedra pulida, sin embargo, era conocido desde los tiempos precerámicos, en particular para las hachas de piedra, las piedras de moler y los adornos personales (brazaletes, collares). Es luego 
probable que la punta de piedra pulida no aya sido utilizada más temprano porque esta necesidad era inexistente. Este hecho debe sin duda estar ligado a la escasez o inclusive ausencia de animales de grandes dimensiones cuya caza justificaba el uso de armamentos de puntas de piedra.

Para una mayor claridad, presentamos la evidencia arqueológica bajo la forma de la Tabla 4. Muelle (1957), Daggett (1984: 182-186 y fig.: 5.235.25) y Brennan (1978) proponen una descripción muy detallada, la cual permite evidenciar que las puntas encontradas en los valles de los ríos Moche, Nepeña, Casma o en Chavín (Lavallée 19691970), eran muy similares. Si bien algunos autores las fechan del Horizonte Temprano, abogamos (Chamussy 2009), que, por su asociación cronológica con el encuentro entre las poblaciones del Horizonte Temprano con aquellas del inicio del periodo Intermedio Temprano, se las puede considerar como elemento diagnóstico de esta fase.

Pero en el valle del río Nepeña, contrariamente a Cerro de Arena, las había de diversos tamaños, con un largo que podía variar entre los 3 y $16 \mathrm{~cm}$, el ancho de 3 a $15 \mathrm{~cm}$ y el grosor de 2 a $7 \mathrm{~mm}$ en la base; eran muy puntiagudas mientras que ambos lados eran afilados de manera tal a poder cortar o picar; algunas llevaban marcas de colocación de mangos. Desgraciadamente, Daggett no da ningún detalle acerca de estos puntos de enganche de los

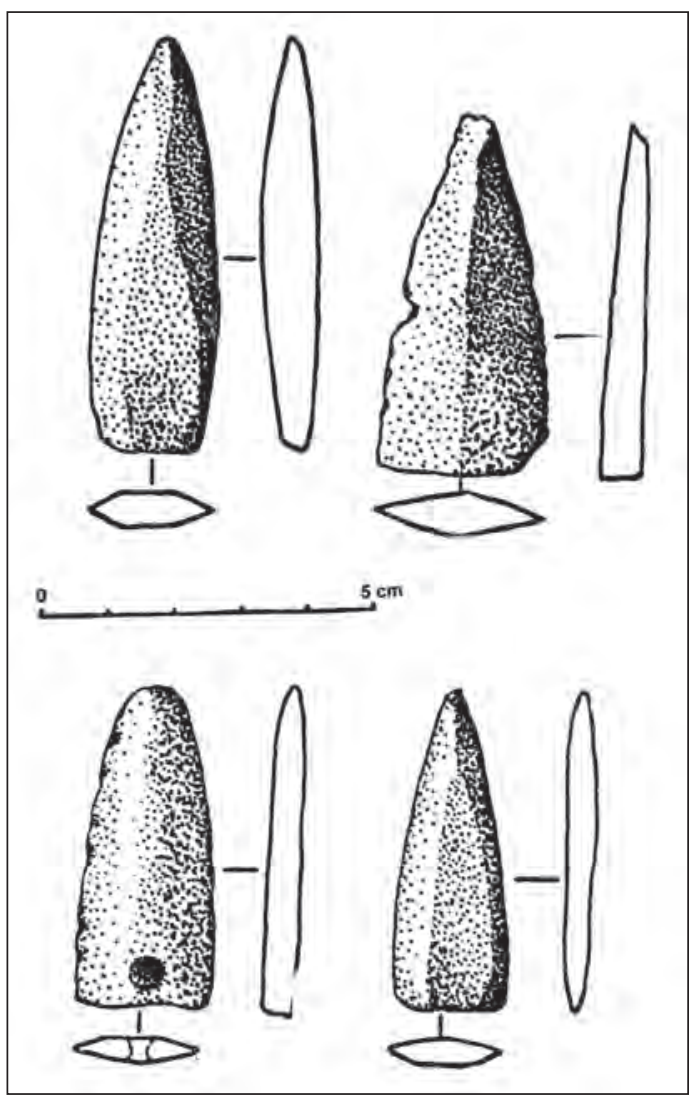

Figura 10. Puntas pulidas Huaraz, Chavín. Lavallée 1970: lam 10. mangos o sobre las zonas de ruptura, lo cual no permite saber si se trataba de cuchillos con mango, de venablos o de lanzas. Sin embargo, contrariamente a las puntas de Cerro de Arena, había aquí puntas cuyas pequeñas dimensiones habrían fácilmente permitido su uso como armazones de venablos. Cabe resaltar que, al igual que Brennan, Lumbreras (1980: 271) no aboga por su eventual uso doméstico o para la caza, y les otorga exclusivamente una función de armas de guerra, lo cual es también nuestra tesis.

Tabla 4. Huella de propulsores o ganchos en el Periodo Inicial y Horizonte Temprano

\begin{tabular}{|l|l|l|l|}
\hline Sitio & Valle o cuenca & Tipo & Referencias \\
\hline Buena Vista* $^{*}$ & Chillón & $\begin{array}{l}\text { Mango de } \\
\text { madera }\end{array}$ & Benfer 2010: 48 \\
\hline Curayucu 1 & San Bartolo & gancho & Engel 1956; Lanning 1960 \\
\hline Arenal de Ventarrón & Reque & gancho & Alva Menezes, comunicacion personal 2009 \\
\hline Quecher Yanacocha & Cajamarca & gancho & Vasquez Sanchez, com. personal 2011 \\
\hline Chanquillo & Casma & $\begin{array}{l}\text { Propulsor } \\
\text { entero }\end{array}$ & Ghezzi 2008, fig.15 \\
\hline
\end{tabular}

* Re-ocupación del Formativo en un sitio Precerámico.

** Una tumba intrusiva junto a cuencos de estilo Cupisnique. 


\section{ARCO Y FLECHAS}

Se determina la presencia arqueológica del arco a partir del estudio etnológico comparado de los pesos y medidas de puntas de flecha en relación a aquellos de los venablos lanzados con propulsores, pues los materiales perecederos constitutivos del arco desaparecen totalmente (Blitz 1988: 125, 126). Cuatro son las ventajas del arco sobre el propulsor (Otterbein 2004: 65): mayor alcance (150 metros) : mayor discreción, sobre todo en medios forestales; posibilidad de llevar más flechas por ser más livianas y cortas que los venablos; aprendizaje más fácil y rápido; en cambio, el arma no puede ser utilizada en los combates cuerpo a cuerpo, como es el caso del propulsor que se utiliza con un solo brazo, aunque la selección de una u otra arma no corresponda necesariamente a un progreso tecnológico y dependa mucho del contexto (Ibid.: 133-134). Según Testart (1985: 119) “[...] la reticencia de sociedades estatales de la América nuclear, de los Andes a México, a utilizar el arco y a preferirle el propulsor, este arcaísmo aparente [puede] hallar su fundamento en la llegada tardía del arco pero también en la débil importancia económica de la caza en estas sociedades, o también desde una voluntad, -no-reductible a imperativos técnicos sino explicados por motivos ideológicos-, de preservar elementos culturales tradicionales".

Es probable que el arco no haya llegado a América con las primeras migraciones. No se sabe si fue motivo de un reinvento o si llegó con una de las olas migratorias siguientes (Ibid.: 119). Lo cierto es que su presencia está formalmente atestiguada en el Ártico Canadiense entre 2500 y 800 a.C.

En la Suramérica, es probable que el arco y la flecha hayan comenzado a ser utilizados en la inmensa selva tropical húmeda que cubre los dos tercios del continente, pues se trata de un arma ideal para la caza en medio forestal cubierto (Métraux 1963), aunque en el norte de Chile, en el sitio Morro I (Arica), con fecha 3450-1750 a.C., cuatro ejemplares indiscutibles de arcos han sido encontrados, lo cual parece confirmar la presencia precoz del arco en la costa norte de Chile (Standen 2003: 175207).

Algunos consideran su presencia como muy antigua en los Andes, en base a algunas representaciones en petroglifos o pinturas rupestres: entre las más conocidas de ellas, las pinturas de Toquepala, un personaje parece sujetar en sus manos un arco, o un báculo (Guffroy 1999: 28-30 y fig. 5 y 8). Este último autor interpreta asimismo las pinturas del abrigo rocoso de Oqhotera (Fig. 2 supra), posiblemente contemporáneo de Toquepala, como una batalla entre arqueros, aunque se vio más arriba (propulsores) que el autor de su descubrimiento afirma que se trata de propulsores y no de arcos (Hostnig 2003, 2007).

Velarde (1980: 68) estima que algunas puntas muy pequeñas de piedra, que no habrían podido ser lanzadas sino únicamente mediante flechas muy livianas, dan cuenta de su presencia en el periodo Inicial y Horizonte Temprano. Klink y Aldenderfer (2005: 52-54) piensan que la forma más pequeña de puntas de obsidiana de su tipo 5d (largo comprendido entre 16 y $26 \mathrm{~mm}$ ), está probablemente vinculada a la adopción de la tecnología del arco y la flecha de su periodo Arcaico Terminal (4400-3600 antes del presente) en la sierra, y se irá acentuando durante el periodo Formativo. Llegan hasta proponer que la presencia del arco podría estar ligada a guerras territoriales, tal como lo sugieren las pinturas rupestres de Río Huenque. Pero fuera de estas hipótesis, hay que subrayar que no se tiene prueba material alguna al respecto, pues los restos de los arcos como tales nunca han sido encontrados y, tal como lo subrayan los autores (Ibid.: 52), estas puntas podían muy bien servir para venablos o azagayas. En la cita ya mencionada de Bartolomé de las Casas (1550), quien describe un periodo Antiguo que Donnan (1978: 87) estima ser el periodo Intermedio Temprano, se dice: "no tenían flechas ni arcos [...] [en las sierras]".

En el inmenso corpus iconográfico Mochica, no existe, -hasta donde yo sepa-, representación alguna de arcos ni de flechas. Tampoco se encuentran las huellas arqueológicas pertinentes en ese sentido en las numerosas tumbas recientemente excavadas por lo que se presume fuertemente que esta arma no fue utilizada ni para la caza, ni para la guerra. 
Al inicio del Imperio Wari (Horizonte Medio), el uso del arco es formalmente reportado en una gran urna encontrada en Conchopata (Ayacucho), en la cual guerreros armados están representados (Bischof 2005: 74-75). Uno de ellos, arrodillado en la posición clásica en una embarcación de totora (Fig. 11), levanta un arco y flechas en una mano, mientras que en la otra sostiene un escudo rectangular decorado con figuras de felinos (Isbell 2001: 121 fig. 11). Bischof (2005: 76) escribe a propósito de estas representaciones que "no se puede eliminar la alternativa según la cual no se trate de un acontecimiento histórico en el sentido occidental del término, sino más bien de un suceso mítico tal como la llegada de ancestros fundadores"; no obstante, Isbell (2001: 50) sugiere que la escena ocurre en el lago Titicaca durante un cruce de armas entre las fuerzas de Tiahuanaco y de Wari.

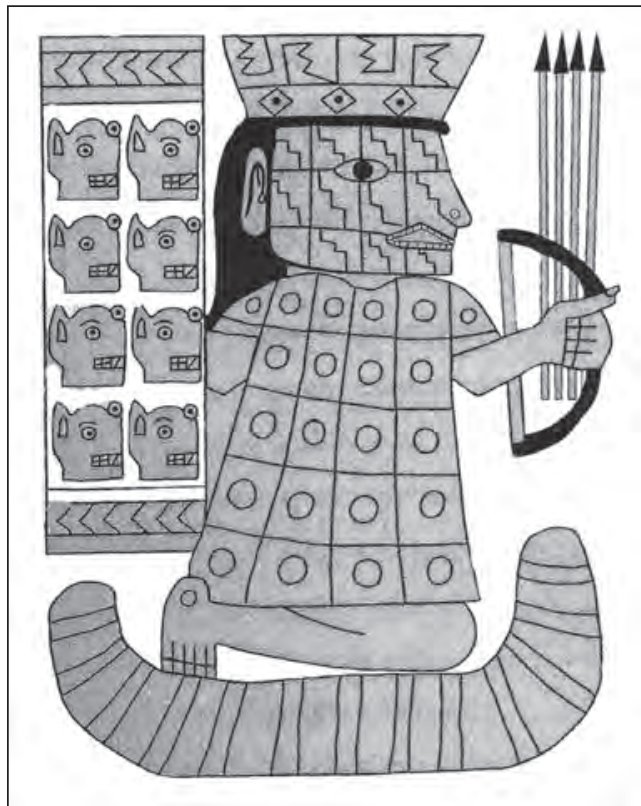

Figura 11. Wari Conchapampa, guerrero con arco y flechas balsa de totora, según Isbell 2001: fig. 11.

En el imperio inca, el arco se denomina huacachina, mientras que la flecha es llamada huacachi. En el diccionario quechua de Holguín (1608), se lee: "Ppecta o picta: arco para tirar; ayçasca piccta: arco flechado; Huach hini: flechar; huach hi: flecha", mientras que en el diccionario aymara de Bertonio (1612), se anota: "Micchi: arco para tirar, flecha para tirar; tirarla: Micchitha; flechero: Micchiri".

Su presencia es efectivamente reportada: "fue el arma principal de los ejércitos del Imperio quechua [inca]" (Urteaga 1928: 149); según Quiroga Ibarrola (1958: 387, 388), había compañías de "flecheros" en el ejército inca, pero el arco no es citado por el cronista Francisco de Jerez (1534). Al parecer, el uso del arco y las flechas era reservado a grupos de combatientes específicos sin duda originarios de regiones de selva tal como los Chachapoyas, o del Ecuador, tal como los Cañaris (d'Altroy 2008: 227), aunque, según el cronista Pedro Sánchez de la Hoz (1534) citado por Bischof (2005: 75), los españoles encontraron estas armas entre el material almacenado en la fortaleza de Sacsayhuaman, luego de haberla conquistado. En la obra de Guamán Poma de Ayala, el arco aparece únicamente entre las manos de los capitanes sexto y decimotercero, ambos representados cazando felinos en las montañas inhóspitas del Antisuyu (Guamán Poma 1613: 154-5; lam. 155 y 167), así como junto a un habitante del Antisuyu haciendo sacrificios a sus ídolos ante un felino.

Al parecer, pues, aunque este punto sea aún motivo de debate, el arco y la flecha nunca fueron utilizados a gran escala en el área andina, quizás a causa de la escasez de la madera adecuada para la fabricación del arco en la sierra o en la costa (Métraux 1963: 229). Además, hay que subrayar la ausencia total de huellas de heridas por flechas en los entierros del área centro-andina.

\section{HONDA}

La honda (huaraca en quechua, korahua en aymara), arma de caza y de guerra, aparece por vez primera en el Próximo Oriente durante el Neolítico (Korfman 1973: 38; Ferrill 1997: 24, 25) ${ }^{9}$; su uso nunca ha sido abandonado desde aquel entonces: Egipto (una honda ha sido encontrada en la tumba de Tutankamon, enterrado en 1325 a.C.), Mesopotamia, Persia, Grecia (referencias por ejemplo en la 
Iliada, Tucídides, el Anábasis de Jenofonte), romanos, cartaginenses, Edad Media. Es el arma de David contra Goliat, del débil contra el fuerte. Ésta es sin duda la razón por la cual sigue siendo el arma de la plebe, del pueblo, de la infantería. Fuera de Europa, se la encuentra en África y en Asia, excepto en Australia (Heizer et al. 1952: 139).

En América, se trata quizás de un reinvento, pues no se encuentra ninguna huella de su presencia entre los paleoindios de América del Norte o del Sur. En el actual territorio de Estados-Unidos, el ejemplar más antiguo parece ser una honda de algodón encontrada en la tumba de un niño de seis años en Lovelack Cave, Arizona (Ibid.), cuya fecha no es anterior a 2482 \pm 260 a.P. Según mencionado por el autor, no era empleada sino como juguete por los niños, pero es muy común para la época histórica (Ibid. fig. 68).

En un estudio reciente, Hernández (2002: 116) sugiere que la idea de la honda habría nacido del manejo de la boleadora, al descubrir accidentalmente los cazadores de guanacos que podían guardar en mano la cuerda que ata la boleadora.

Quién como Mejía Xesspe para describirla en mejores términos: "Consta con tres partes: una central, de forma romboidal para contener la piedra arrojadiza; y dos cabos trenzados o torcidos, una de las cuales tiene una asa para sujetar con el dedo meñique y otro una borla aplanada para impulsar la velocidad de la piedra. De ahí que la waraka constituye un arma de combate, a distancia de diez a veinte metros o más, mediante el lanzamiento de piedras redondas o angulosas" (Tello y Xesspe 1979: 349). Su alcance varía de 27 a 100 metros (Keeley et al. 2007 tabla 1). El nombre quechua "huaraca", tiende a ser generalizado por los autores aunque algunos emplean el término "lazo" (Urteaga 1928: 128). Este último autor explica que la palabra "lazo" se refiere al cinturón o cinta de tela que sujeta la huara o pantalón, dando origen al nombre "huaraca" (Ibid.: 132).

Es preciso acotar que la honda tenía usos muy numerosos, pues también era utilizada por los niños en la caza de pájaros (Salas 1930: 84), por las mujeres a manera de sacos para los granos que llevaban consigo para la siembra, como gorro para los bebés (Quiroga Ibarrola 1958: 393; Salas 1950: 85) o a manera de tocado entre los nascas (Tello y Xesspe 1979: 417-418; Inca-Perú 1990 t. 2: fig.146; Proulx 2006: fig. 5.256); inclusive servía para halar a las embarcaciones durante el cruce de ríos: los dos extremos fijados en la embarcación, el nadador colocaba su cabeza en el soporte para poder liberar los brazos (Garcilaso de la Vega, citado por Donnan 1978: 93). En Paracas, era usada para sujetar las tablas alrededor de la cabeza del niño durante el proceso de deformación craneana.

\section{Precerámico}

Al igual que el propulsor, la honda no aparece en los sitios del área centro-andina antes del Precerámico VI. ${ }^{10}$, mientras que era conocida en la selva (Métraux 1963). Es probable que no haya sido necesaria aquí debido a una subsistencia esencialmente orientada hacia la pesca y la horticultura, sobre todo en la costa. Las primeras hondas arqueológicas vienen no obstante de la costa; no hay testimonio arqueológico alguno de aquella en los sitios de los abrigos rocosos de la sierra, sin duda por ser de un material perecedero que no se pudo conservar sino en el clima seco de la costa.

Las más antiguas se hallan en Huaca Prieta (Costa Norte), hacia 1800 a.C., pero según su descubridor, -Junius Bird (1948)-, y al igual que en el caso de Lovelack Cave en Nevada, se trataría de juguetes de niños. Otras han sido encontradas en Chilca, (Engel 1988: 19). En Asia (en la Costa Sur) aparecen en un pozo de almacenamiento así como en una tumba (Fig. 12), junto a dos propulsores, puntas de obsidiana y cuarcita, un mazo y algunas lanzas dudosas (Engel 1963b: 57, fig. 40). Estas hondas, de

10 Engel (1991: 75) habla de una honda de hebras de lana en el sitio 514 de Paracas, cuyo fechado tiene por único fundamento su superposición al sitio 96 (Precerámico sin algodón). Si bien no se ha encontrado algodón en los vestigios de viviendas o tumbas, en nuestro criterio, este sitio debe ser del Precerámico Final. 


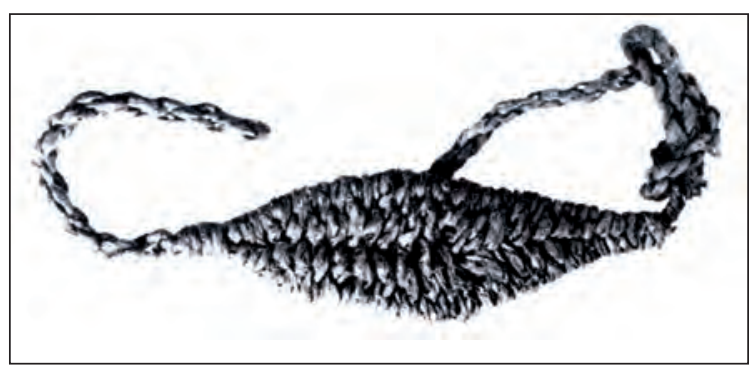

Figura 12. Honda de Asia, según Engel 1963: fig. 140.

cañas entrecruzadas, son similares a dos más encontradas en río Seco en la costa CentroNorte (Wendt 1964), así como a otra encontrada en Otuma en la costa sur (Engel 1963b: 57). El soporte mide $13 \times 4 \mathrm{~cm}$ aproximadamente, mientras que los cordones se terminan cada uno por un aro.

\section{Periodo Inicial y Horizonte Temprano}

Si bien la presencia de la honda se confirma para el fin del Precerámico, extraña que no se encuentre ningún ejemplar arqueológico de honda ni de proyectiles para honda en las regiones norte y centro norte para el periodo Inicial así como el inicio del Horizonte Temprano, con excepción de dos especimenes completos y dos fragmentos encontrados por Brown Vega (2008: 327, 2010: 177, 181) en Acaray, aunque este sitio es una fortaleza que contó con dos ocupaciones muy distintas, la una situada hacia el final del Horizonte Temprano, y la otra, en el periodo Intermedio Tardío; la autora (141-145) no se pronuncia acerca de las dataciones de estas hondas. Las únicas representaciones iconográficas son aquellas de Pójoc, cerca de Chavín (Fig. 13), -dudosa, por ciertoen donde Burger (1982: 30) interpreta el objeto sujetado en la mano izquierda del personaje como una honda ${ }^{11}$, aunque él mismo reconoce más adelante que nunca se han encontrado representaciones de honda en el arte Chavín, y de la fortaleza de Chanquillo, en la desembocadura del río Casma en la llanura costera, con fecha del final del Horizonte Antiguo, en donde Ghezzi (2006: 72 y fig.3.4 h) encontró la representación miniatura de una

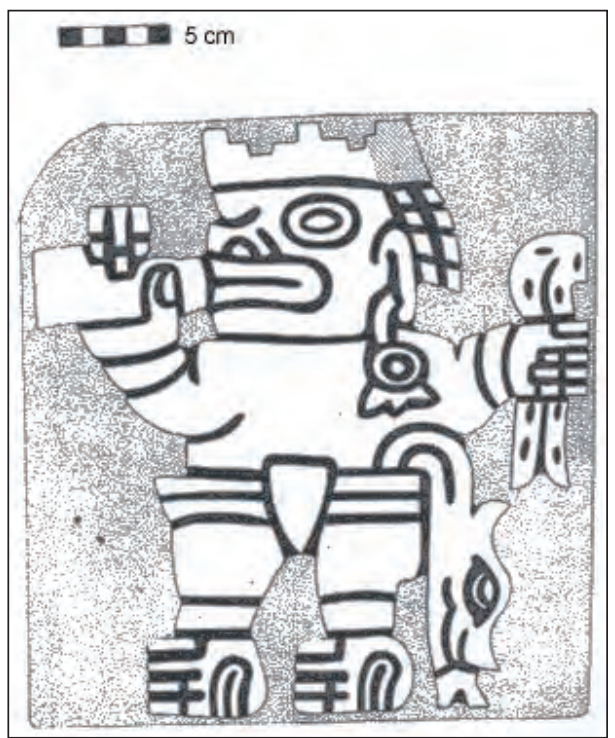

Figura 13. Pojoc, guerrero con pututu y honda o shaman bebendo sustancia alucinógenica (según Burger 1982: fig 19). honda de cerámica, desprendida de la figura del guerrero sobre la cual parece haber estado colocada. En nuestro criterio, este hecho se debe a la guerra acontecida entre el final del Horizonte Temprano y del Horizonte Blanco sobre Rojo (Chamussy 2009: 263). Se puede concluir que la honda es muy escasa o inexistente durante el periodo Inicial en la sierra y las costas norte y centro norte y aparece al final del Horizonte Temprano por motivo de los primeros enfrentamientos con las poblaciones Blanco sobre Rojo.

En cambio, en Paracas (Costa Sur), se trata de un arma de caza muy común. En Paracas Cavernas, se encontraron muy numerosos ejemplares en los fardos funerarios (Tello y Xesspe 1979: 219 y fig. 63.2 y 64.1; 349 y fig. 95. B; 399; 418-419 y fig. 116). Xesspe las describe como armas de combate de $1,2 \mathrm{a}$ 1,5 metro de largo, generalmente hechas de fibra vegetal (maguey) pero no hay certeza alguna de que no hayan sido utilizadas únicamente como arma de caza. En la tumba 382 solamente, había 37 de fibra de maguey (Carrión Cachot 1949: 51). No obstante, hecho destacable, no se encuentra ninguna repre-

11 Por nuestra cuenta hemos más bien planteado (Chamussy 2009: 100) la representación de un sacerdote injiriendo un alucinógeno con la mano derecha y llevando un cactus de San Pedro en la izquierda. 
sentación iconográfica de honda ni en los magníficos mantos funerarios, ni en las cerámicas, mientras que todos los demás tipos de armas que se encuentran en las tumbas (propulsores, venablos, mazos) están representados en la iconografía. Sin duda existe algún motivo que explique esta escasa representación iconográfica: no cabe duda que la iconografía Paracas, al igual que la de Cupisnique/Chavín, es un arte religioso y como tal, "basado en la analogía y la metáfora hasta un punto extremo" (Burger 1988: 130), lo cual excluye toda representación de la realidad. Los personajes representados en la iconografía de Paracas son todos "seres supremos" o dioses, con los atributos de poder sobrenatural que se les asocia. No obstante, una de las atribuciones más comunes que se les da es su poder de regeneración, simbolizado por la sangre derramada y las cabezas-trofeo, que permiten a la vegetación reproducirse; los atributos necesarios para ejercer ese poder son el tumi y el báculo, explicándose así el origen de las representaciones más comunes encontradas en la iconografía de Paracas: el dios de los báculos y el dios con un tumi en una mano y una cabeza trofeo en la otra.

\section{Periodo Intermedio Temprano}

La situación se invierte y la honda es a menudo representada en la iconografía, tanto en Nasca como entre los Mochicas. Entre estos últimos, nos encontramos en una situación exactamente inversa a aquella de Paracas: en las tumbas de la élite se encuentran porras y propulsores, pero nunca se halla honda alguna. En contrario, la honda es el arma más representada después del mazo en la cerámica pintada, pero un examen atento de las numerosas reproducciones de vasijas Mochicas (fases I-IV) demuestra que, por un lado, en la inmensa mayoría de casos, las hondas sólo son utilizadas para la caza (Kutscher ([19671950]: fig. 1; Bischof 2005: 77) y no en los combates entre humanos (Bourget 2001a); por otra parte, la honda no aparece nunca en las representaciones escatológicas que ponen en escena divinidades, como por ejemplo en las numerosas figuraciones de la rebelión de los objetos, o aquellas de sacrificio (Kutscher 1983; Bonavia 1994; Lavalle 1984; Hocquenghem 1987; Donnan y McClelland 1999; Alva 2001). En particular, en la "parafernalia del guerrero", tantas veces representada, la honda casi nunca es figurada. Existen sin embargo excepciones a esta regla. En una vasija de Berlín (Hocquenghem 1987: fig. 84), dos guerreros con cascos de diferentes tipos se enfrentan con sus porras, pero al parecer, hondas y proyectiles se hallan dispersos en el suelo alrededor de ellos; un combate de dos guerreros, de los cuales uno levanta una porra con la mano derecha y parece hacer girar una honda en la mano izquierda, es representado en una nariguera de oro (Lumbreras 1980, lam. 368).

Curiosamente, entre los vecinos y coetáneos de la sierra, -los Recuay-, se encuentran pocas representaciones de armas fuera del mazo (DeLeonardis y Lau 2004: 86). Las dos excepciones que conocemos son aquella de un guerrero Recuay (Fig. 14) que forma parte de un combate entre Recuay y Mochica en la vasija de Lührsen (Lau 2004), y la de un tazón evertido o compotera que se encuentra en el museo Amano de Lima, la cual representa asimismo un combate entre Recuay y Mochica (Chamussy 2009: lam. 36). Estos dos ejemplos parecen confirmar el texto de Las Casas y demostrar que, contrariamente a los Mochicas, la gente de montaña utilizaba la honda en la guerra.

Los fardos funerarios de Necrópolis, contemporáneos del inicio de periodo Intermedio Temprano, contienen cada uno varios ejemplares de hondas (con un total de 147) (Tello y Xesspe 1979: 475). Pero según Yacovleff y Muelle (1934: 114), eran principalmente ceremoniales contrariamente a Paracas Cavernas y no podrían haber sido utilizadas como armas pues, entre otras cosas, eran demasiado cortas. En los suntuosos mantos funerarios de Brooklyn y de Göteborg, de estilo Nasca 1-2, ambos provenientes de excavaciones clandestinas en Paracas, se encuentra la representación de un dios con una honda en una mano y una cabeza-trofeo en la otra. Según la interpretación de Makowski, la escena entera representa divinidades que presiden algún tipo de premisa agrícola. El autor establece el vínculo entre esta divinidad femenina llevando una honda y un grabado de Guamán Poma (1613: 1168) llamado "cuidadores de cosecha", lo cual lleva a pensar que la honda podría perfectamente ser el arma de caza para los pájaros del campo en el momento de la cosecha (Makowski 2002; 2003: 


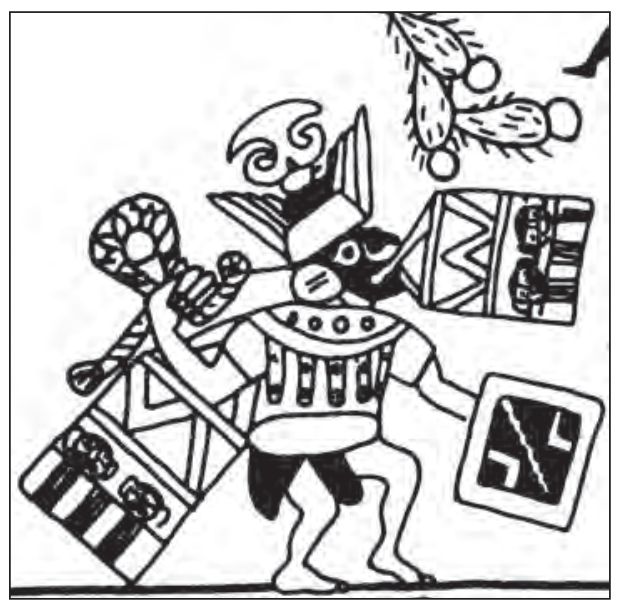

Figura 14. Guerrero Recuay con honda (detalle segun Wilson 1988: fig. 339).

107). De hecho, sería legítimo preguntarse si, al igual que entre los Mochicas, el papel esencial de la honda no era más bien la caza de aves y de animales pequeños.

Entre los Nasca, se encuentran hondas en las tumbas y en la iconografía, pero en cantidades pequeñas en comparación con las numerosas representaciones de propulsores y sobre todo, de cuchillos de sacrificio asociados a las cabezas-trofeo. Es luego con cierta exageración que Proulx (2001: 127), fehaciente partidario de la guerra nasca, escribe: "las hondas eran las armas más comunes pues eran fácilmente hechas y transportadas, inclusive por la persona más humilde. Las tumbas Nascas - a menudo huaqueadas-, dan cuenta de una gran cantidad de hondas dejadas por los huaqueros, quienes les otorgaban poco valor. La cerámica representa a menudo un hombre con una honda enrollada alrededor de su tocado cuando no la usaba. Las hondas podian también ser usadas para la caza, para repeler a los depredadores, así como para la guerra, y aparecen como una añadidura normal al traje masculino". En la iconografía, aparecen a menudo entre las manos de un llamado "guerrero" según Proulx (Fig. 15) o enrolladas alrededor de su tocado a manera de turbantes decorativos (Seler 1923, fig. 141, 142, 149; Kroeber y Collier 1998: 52). Otra representación de honda aparece en un bastón de mando pintado, con fecha del principio de la fase Nasca (Lapiner 1976: fig. 467-468, museo de Göteborg) y en una jarra Nasca 3-4, representando humanos llevando en una mano un propulsor, y en la otra, un puñado de venablos y una honda (Lapiner 1976: fig. 501), o también una vasija antropomorfa del museo de Munich, cuyo personaje sostiene una honda tendida entre sus dos manos y otra a manera de tocado (IncaPérou 1990 t. 2: fig.146). En las excavaciones, la cantidad de hondas Nasca es baja (Bischof 2005: 80). No obstante, en su estudio del valle de la baja cuenca del río Nasca y del río Grande, Proulx ha encontrado varias hondas en tumbas, algunas con colores (Proulx 1998: 6, 25, 41, 98, 106, 121; 2007: RN-28, RG33, RG-45). En Chaviña (Acarí), Lothrop y Malher describen la parte central de una honda encontrada en una tumba de un personaje de élite, conjuntamente a propulsores (Lothrop y Malher 1957: 39). O’Neale (1937: 201y lam. 48 a, c \& d) describe varios ejemplares originarios de Cahuachi. Kroeber y Collier (1998: 52, 78, 80) han asimismo encontrado varias hondas en las tumbas A1-5 y 1j-13 de Cahuachi, mientras que Strong encontró una en 1953 (tumba 37 de una mujer) (Proulx 2006: 173), y otros sitios (Ibid: fig. 4.6).

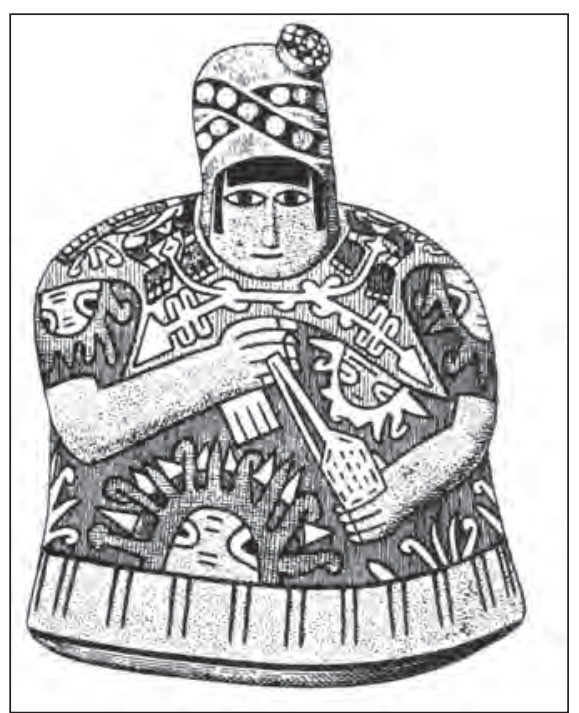

Figura 15: Guerrero nasca sujetando una honda (Seler 1923, fig. 9).

\section{Horizonte Medio}

La presencia de municiones de honda en Galindo (Bawden 1982) así como en los sitios de Pacatnamú y Charcape (J. \& T. Topic 1987 : 49) deja presuponer el uso de la honda como arma de guerra en el Horizonte Medio. Tenemos también la representación de una honda en los manos del Ídolo de Pachacamac (Ángeles y Pozzi-Escot 2010: 190) 


\section{Intermedio Tardío y Horizonte Tardío}

En la Sierra norte, en la época de los señores de Cuismancu (Cajamarca) y Huamachuco, es decir, durante el periodo Intermedio Tardío, la divinidad suprema local, Catequil, era representada llevando una honda en cada mano, con la cual producía rayos y truenos (Silva Santisteban 1985: 23). Los habitantes de Cusimancu tenían la costumbre de llevar -a manera de tocado y como señal distintiva-, las hondas simbólicas de Catequil (Cobo 1653 [1964]: cap. XXIV: 123190; Silva Santisteban 1986: 23).

La honda meramente decorativa aparece en sepulturas incas (Yacovleff y Muelle 1932). La importancia del significado simbólico de la honda entre los Incas es atestiguado por la representación frecuente del dios del trueno y el relámpago, Illapa, quien aparece con una honda en una mano y un mazo en la otra (Cobo 1653[1964]: cap. VII: 16440). El Inca Huayna Cápac no despreciaba el alzar él mismo la honda, tal como lo muestra un grabado de Guamán Poma (1613: lam. 33), en donde se ve al Inca llevado en andas por cuatro hombres; otro grabado del mismo Guamán Poma representa a Pachacuti levantando una honda (Ibid.: lam. 108). Su uso ritual durante la fiesta del Capac Raymi es largamente descrito por el Padre Cobo (1653[1964]: cap. XXV). En el curso de la ceremonia de investidura de los orejones en la fiesta de Raymi, los parientes regalaron à los 'impetradores' una honda (Juan Diez de Betanzos [1551] 1968, cap. XIV].

La honda inca, de $2 \mathrm{~m}$ de largo en promedio, era de lana y de cuero, a veces decorada con alambres de oro y de plata para la nobleza, y se llevaba amarrada a la cintura o a manera de ornamento de tocado (McIntyre 1973: 780). Había, en el ejército Inca, grupos especializados de 'honderos' (Quiroga Ibarrola 1958: 388) y Cieza de León estima que sólo la escolta del Inca contaba 5000 honderos (Urteaga 1928: 131). Según Means (1931: 318-19), habría sido llevada por los ejércitos incas al Ecuador, a Argentina o Chile durante su conquista, pero nunca habría logrado remplazar completamente el arco y la cerbatana en esas regiones, a pesar de que los Españoles la hayan descubierto entre las manos de los Indígenas de la Puná (Zárate 1830 vol. 1: 28, citado por Means 1931: 319). Varios otros grabados de Guamán Poma (1613: lam.161; lam. 157) representan enfrentamientos entre incas y Chachapoyas o incas y mapuches, en donde se ve uno de los soldados incas levantar una honda. El Padre Cobo escribe: "De lejos empleaban las hondas hechas de lana o de cabuya, en que eran grandes certeros. Usábanlos casi todos los de este reino, particularmente los serranos que eran extremados honderos" (Cobo 1653 [1964]. Cap. IX). El historiador peruano Víctor López de Mendoza (1980:338) escribe que fue una de las armas predilectas del ejército inca y que los soldados incas se lucían por la precisión y la fuerza con las cuales lanzaban los proyectiles de piedra del tamaño de un huevo de gallina, con una fuerza tal que podían matar a un caballo y su jinete. Fue de hecho con piedras envueltas en algodón incendiado enviadas con hondas que los Incas prendieron fuego a los techos y sembraron el pánico entre los habitantes de Cusco, durante el sitio de 1536 (Pedro Pizarro [1571] 1944: 103). Fue asimismo el arma que más hizo sufrir a los españoles durante el sitio de Sacsayhuaman, y causó más particularmente la muerte de Juan Pizarro, hermano del conquistador (Garcilaso t. I lib. 2 c. XXIV). Luego de la última retirada de Túpac Amaru, en 1572, un general inca traicionó a su jefe y reveló a los Españoles que, en la fortaleza de Huaynuná Pucara, "se habían preparado numerosos amontonamientos de piedras destinados a servir de proyectiles para las hondas de los Indígenas" (Hemming 1971: 361). Se trata luego de un arma inca particularmente temida por los españoles.

\section{PROYeCTILES DE PIEDRA REDONDA}

Estos proyectiles pueden servir tanto para la caza como en los combates de campo raso, o desde las murallas de sitios defensivos y debían principalmente ser utilizados en los sitios defensivos, en donde se tiene tiempo de recoger en las playas o en el lecho del río los proyectiles de forma y tamaño adecuados, de llevarlos hasta el sitio y luego de almacenarlos (Ghezzi 2006: 72-75; Brown Vega 2008); de hecho éstos son los únicos lugares en donde se los encuentra. 
Korfman (1973) fue uno de los primeros en sugerir que los descubrimientos de cantos redondos, -amontonados lejos de los lechos fluviales o de las playas-, eran proyectiles. Éstos son considerados como una de las evidencias más contundentes de guerra (J. \& T. Topic 1987: 48), pues sugieren una premeditación propia de una logística puramente guerrera. Se encuentran a menudo amontonamientos separados por una distancia de 2 a $3 \mathrm{~m}$, espacio necesario para que dos honderos no se estorben mutuamente. Lanzados desde lo alto de las murallas, su alcance es muy variable dependiendo de si son lanzados con la mano o con una honda, y siguiendo el dispositivo de la muralla Un estudio muy completo ha sido realizado por Brown Vega (2008: 135-138; Brown Vega y Craig 2009) en el caso de la fortaleza de Acaray en el río Huaura (Costa Centro).

Generalmente de forma esférica y del tamaño de un huevo de paloma, el diámetro promedio de estas municiones varía entre 2,5 y $8,7 \mathrm{~cm}$, aunque las más grandes eran quizás lanzadas con la mano (Brown Vega $2008: 329$ ) : tabla 5

Tabla 5: Dimensiones para las municiones de hondas.

\begin{tabular}{|l|l|l|}
\hline Sitio & Autor & Dimensiones $\mathbf{( c m})$ \\
\hline Chanquillo & Ghezzi 2006: 72 & $7,3 \times 3,9$ \\
\hline Ostra pile 1 & Topic 1989 anexo & $6,9 \times 5,2 \times 4$ \\
\hline Ostra pile 2 & Topic 1989 anexo & $5,6 \times 4,3 \times 4,7$ \\
\hline Acaray & Brown Vega 2008: 329 y fig. 10.2 & $8,7 \times 6,5$ \\
\hline Galindo & Bawden 1982; Topic 1989 anexo & $6 \times 4,4 \times 3,1$ \\
\hline Chinchawas & Lau 2001: 393 & $3,1 \times 2,5 \times 1,8$ \\
\hline MV-42 (Moche) & Chamussy (2009) & $5 \times 4 \times 3$ \\
\hline
\end{tabular}

Los dos testigos arqueológicos más antiguos de amontamientos detrás de murallas se encuentran ambos en la desembocadura del río Santa, el uno al norte del río, en Ostra (J. Topic 1989), y el otro al sur de Chimbote, en Playa Catalán (Chamussy 2009: 190-91). Uno y otro provendrían del fin del Precerámico. Además Engel (1966) pretende que ciertas piedras ovoides encontradas en Chilca eran municiones de honda, mientras que Deza Rivasplata (1985) comparte esta idea en lo que se refiere a algunas piedras de forma regular halladas en los estratos arcaicos de Tablada de Lurín. En Culebras, Engel (1958) señala "proyectiles de piedra para hondas", pero no encontró las hondas como tales.

Al igual que las hondas, no se encuentran testigos arqueológicos provenientes de periodo Inicial o del comienzo del Horizonte Temprano. Recién en el Horizonte Temprano Terminal o al inicio del periodo Intermedio Temprano se comienza a encontrarlas en grandes cantidades, en las fortalezas de los valles de los ríos Moche, Santa y Nepeña. Su presencia es asimismo reportada por Brown Vega (2010: 177) en tres fuentes del río Huaura, pero detrás de parapetos o en escondites, y sin relación alguna con las cuatro hondas no fechadas halladas por la autora, y Ghezzi (2006: 74-75) para el mismo periodo en Chanquillo. Éste las encontró en dos ubicaciones distintas: en el lado interior de las murallas externas (supone entonces que cayeron de los parapetos), y al pie de la pendiente de la colina, por lo que propone que se trata de municiones lanzadas sobre el atacante. Ninguna lleva huellas de otro tipo de uso; un estudio comparativo con cantos recogidos en el lecho del río Casma, cerca de la fortaleza, demuestra que su índice de esfericidad y es prácticamente el doble de una muestra recuperada al azar en el lecho del río (Ibid.: 75, tabla 3.5).

Asimismo, durante nuestro trabajo de campo, hemos encontrado numerosos amontonamientos de piedras redondas a lo largo de los muros que cierran el paso en los sitios defensivos de la Fase Salinar en el valle del río Moche (Fig.16), así como en las faldas de Castillo Sarraque (V-72-74 río Virú), alrededor de las fortalezas y murallas defensivas de los ríos Santa, Nepeña y Casma, fechadas del final del Horizonte Temprano o inicio del Intermedio Temprano. En Chinchawas, sitio Recuay 


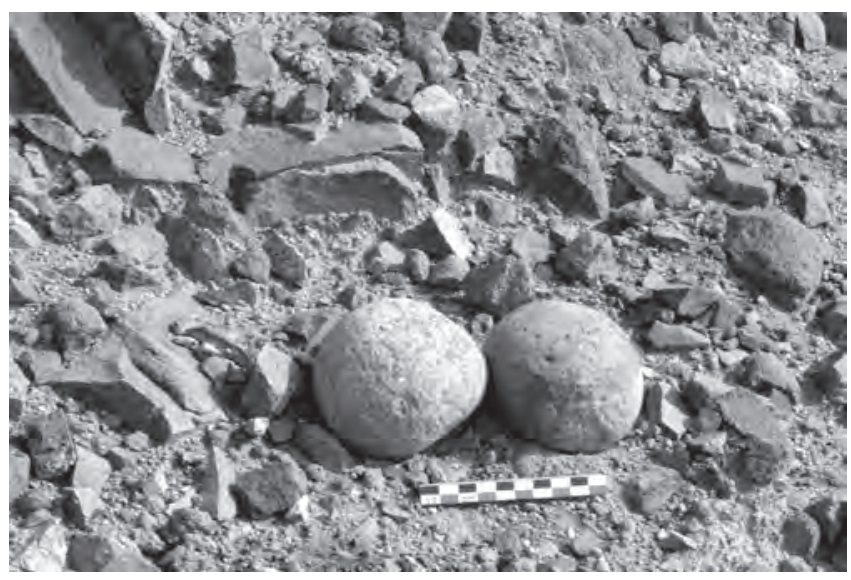

Figura 16. Moche, sitio $M V-42$, piedras redondas detrás de un muro cerrando el paso de una quebrada de acceso (foto Chamussy).

fortificado de la Cordillera Negra, Lau (2001: 393) ha encontrado una gran cantidad de piedras redondas, la mayoría de las cuales -supone- era municiones para honda, y algunas, pulidores. En la ciudad fortificada de Yayno (Conchucos), con fecha de Recuay Medio (400-800 d.C.), el mismo autor (2010a: 430, 2010b: 341) ha encontrado unas cincuenta municiones para hondas distribuidas en el sitio. Bawden (1982) las ha encontrado regularmente distribuidas a lo largo del muro de Galindo (sitio Moche V del río Moche), mientras que los Topic hallaron otros ejemplares en sitios posteriores (Horizonte Medio), en Pacatnamú y Charcape, en el valle de la cuenca baja del Jequetepeque (J. \& T. Topic 1987: 49). Durante el periodo intermedio tardío, se las encuentra en escondites de estructuras defensivas (Stanish 1992: 44-146).

Al incluir grupos de honderos (tal como se vio más arriba), el ejército Inca debió haber utilizado una cantidad importante de municiones de piedra o de arcilla endurecida

En la iconografía, tenemos algunos ejemplos: entre los nascas, Proulx (2006: fig. 5.123) nos muestra un guerrero llevando un haz de venablos en la mano izquierda, así como un báculo de plumas en la mano derecha; alrededor de él se encuentran proyectiles redondos dispersos. También se puede citar a un guerrero Recuay alzando una piedra redonda en la vasija de Lührsen, ya citada (Lau 2004: fig. 7V).

Más tarde, los cronistas llamaron estos proyectiles redondos lanzados con la mano pururauca, "balas de piedra que sueltan de encima del castillo para defenderlo" (diccionario quechua de Holguín 1608). Adicionalmente, los purucaucas de los Incas, de dimensiones comprendidas entre el tamaño de una naranja y aquel de un pomelo, eran el objeto de veneraciones, mientras que su uso conllevaba un carácter más bien mágico antes que belicoso (López Mendoza 1980: 338). Guamán Poma (1613: pl. 153) nos indica guerreros Chanca lanzando purucaucas de este tipo desde lo alto de una fortaleza con ocasión de un ataque inca (Fig. 17). Pururauca (ladrones escondidos) es también el nombre dado por los Incas a las piedras veneradas como guerreros (transformadas en guerreros), que ayudaron a los Incas a rechazar a los Chancas durante la aparición de Wiracocha a Pachacuti (d'Altroy 2008 [2002]: 64, 165).

\section{GALGAS}

En cuanto a las llamadas 'galgas' por los cronistas (Salas 1950: 86) lanzadas desde lo alto de las cimas en los desfiladeros, no son detectables arqueológicamente, aunque se conocen numerosos ejemplos de su uso en contra de los españoles, quienes las temían de forma notoria (Quiroga Ibarrola 1958: 394). Durante el ataque final en contra del último refugio del Inca Tupac Amaru en Vilcabamaba en 1572, el mismo general Inca traidor ya mencionado ofrece al general Toledo la descripción siguiente: "Sobre una distancia de cinco kilómetros antes de llegar a la fortaleza, los Indígenas incas han asegurado las defensas de algunos desfiladeros estrechos por medio de numerosos bloques de rocas", lo cual incita a los españoles a pasar por las cimas, con el objetivo de no ser sorprendidos (Hemming 1971: 361). Su uso es inclusive reportado tres siglos más tarde, con ocasión de la guerra contra Chile (1879-1883), por el general peruano Cáceres (López Mendoza 1980: 339). 


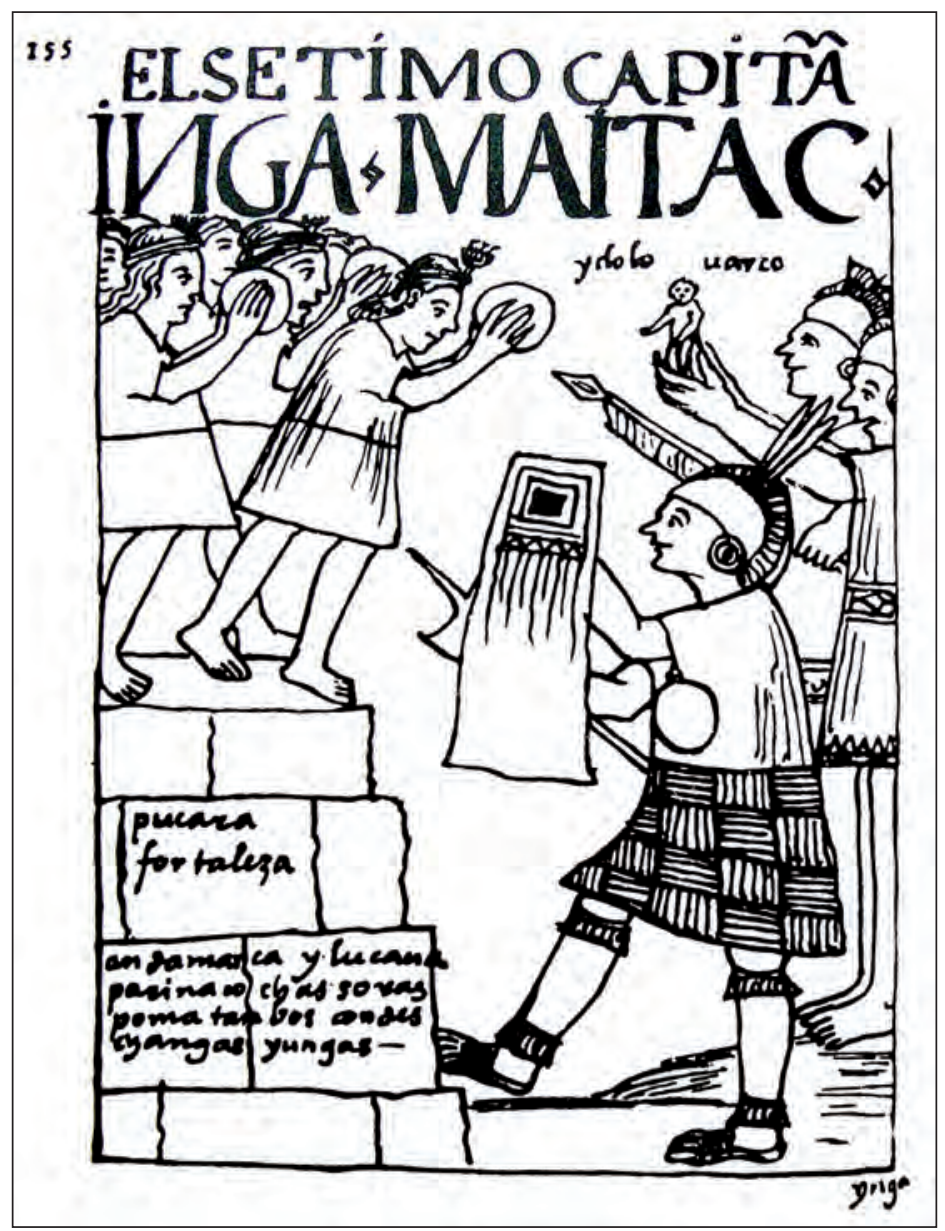

Figura 17. Uso de pururaucas en la defensa de fortalezas inca. Guaman Poma de Ayala 1613: pl. 153.

\section{BOLEADORA O BOLA ${ }^{12}$}

"Bola de piedra punteada o pulida [...] que puede o no presentar una ranura ecuatorial [...] estas bolas, envueltas en un estuche de cuero o colocadas en la cintura mediante una soga que pasaba por la ranura, eran luego atadas a la punta de una soga o de una tira de cuero y juntadas en haces de 203 piezas" (Leroi-Gourhan 1997: 151). Este conjunto es proyectado haciéndolo girar a la manera de los gauchos de la pampa, lo cual tiene como efecto el romper o atar los miembros de los animales perseguidos (Guilaine y Zammit 1998: 95).

En el cono sur, seria muy antigua, pues Dillehay habría identificado bolas en Monte Verde, el sitio paleo-indio del sur de Chile, para el periodo I, con fecha 11 000-10 000 a.C. (Wilson 1999: 154 y fig. 5.15 (b), Bird, en el estrato II Periodo IV (6 000 a.C.) de la cueva Fell en Patagonia (Ibid: 152 y fig. 5.14 (d)), Laming-Emperaire, en el abrigo de Marazzi, tierra de Fuego chilena, con fecha 10000 a.C. (Leroi-

12 La terminología no es fija, y se encuentra uno u otro nombre según los autores. Métraux (1963: 253) escribe: "bolas (Spanish: boleadoras) ». Cabe resaltar que Testart (1985: 123-124) emplea una terminología un poco distinta. Para él, la boleadora o cayo es una bola atada a una tira con la cual se hiere al animal, y las bolas son el conjunto conformado por bolas ligadas entre ellas mediante tiras, y que se lanza sobre el animal. 
Gourhan 1997: 688-689), Cardich, en la cueva n 3 de Los Toldos (Patagonia Argentina), con fecha 7500 a.C. (Ibid. 660) y Legoupil en Ponsonby (isla Guzmán) al $3^{\circ}$ milenario a.C. (Legoupil 2003; Legoupil y Pigeot 2009: 14).

Servía para la caza de guanacos, -cuyas patas se apuntaba-, tal como lo atestigua su descubrimiento en numerosos campamentos de cazadores-recolectores de la pampa Argentina junto a restos de guanacos cazados (Politis et al. 2005). Una variante de la boleadora de dos piedras era usada entre los indígenas de la pampa Argentina para cazar el ñandú, razón por la cual se la llamó ñanducera o avestrucera, también laques. En este caso el cazador apuntaba el cuello del ñandú con el objetivo de asfixiarlo (Hernández 2002: 128).

Aparece tardíamente en la área centro andina, aunque algunos hayan creído reconocerla en diversos periodos desde el Precerámico. En un folleto sobre Caral (Shady Solís 2005: 14), se sugiere a través de una ilustración que las boleadoras existían como armas de caza durante el Precerámico Final. Pero pensamos que la pieza representada bien podría ser un peso de red, del cual numerosos ejemplares han sido hallados en el Precerámico. Huapaya Manco (1978: 261-263, 268 y lam. IV) parece caer en la misma confusión en los sitios de pesca del Precerámico Medio de Chorrillos, Avic y Nunura I en la península de Ilescas. Es efectivamente preciso percatarse que «todas las bolas de piedra con ranura ecuatorial» no son bolas, sino más bien -con mayor frecuencia- sobre todo en los sitios marítimos de la costa del Perú-, pesos de redes de pesca.

No se encuentran huellas de bolas hasta la época Nasca, en donde "la iconografía las pinta como una serie de piedras alineadas a lo largo de una simple soga antes que en sogas múltiples" (Silverman y Proulx 2002: 57). Proulx reproduce tres dibujos de lo que llama bolas, los cuales dan cuenta de cinco a siete piedras (Proulx 2006: fig. 5.122, 5.258, 5.268) y Luján (2010: 112) menciona una boleadora encontrada en la tumba de una mujer de elite en Cerro Salazar al final del periodo. En los tres casos, el hombre alza asimismo un propulsor en el cual se encuentra un ave. Lapiner (1976: fig. 502) y Llanos Jacinto (2009: 221 nota 56 y fig. 11.60 D) refutan esta interpretación, viendo más bien aquí la representación de una honda. De hecho, la presencia de cinco a siete bolas no corresponde a las boleadoras descritas más arriba, tanto entre los Incas como entre los gauchos, las cuales constan de una a tres piedras. La presencia del ave sugeriría que propulsor y honda serían armas de caza y no de guerra, interpretación de Silverman y Proulx, pero no de Lumbreras (1980: 255), quien las considera como armas de guerra.

No se halla luego rastro alguno de bolas hasta los Incas, quienes la adoptaron bajo el nombre de ayllo ("reunir" en quechua), término idéntico a aquel que designa al grupo social o linaje llamado ayllu. Fue inicialmente utilizado para la caza de guanacos y vicuñas. Francisco de Jerez (1534), quien describe las diferentes armas del ejército inca en marcha al inicio de la conquista, no las menciona. En cambio, Cobo, un siglo más tarde (1653), escribe que los guerreros lanzaban un instrumento hecho de "dos piedras redondas poco menores que el puño, asidas con una cuerda delgada y larga una braza, poco mas o menos, tirandolo a los pies, para trabarlos". Durante el sitio de Cusco, los Incas utilizaron esta arma, la cual consistía en "tres piedras redondas que le tiraban a los caballos y los derribaban y algunas veces enredaban al proprio jinete que con mucho trabajo lograba cortar las cuerdas que las unian" (López Mendoza 1980: 337). En Guamán Poma ([613: 182, 206), un arma de este tipo es representada entre las manos de un adolescente cazando aves.

El diccionario quechua de Holguín (1613) la denomina ayllo o rihui, y la describe de la siguiente manera: "Bolillas assidas de cuerdas para trauar los pies en la guerra, y para caçar fieras, a aves y tirar a trauar pies y alas". En los Andes, es también llamada liwi (Lumbreras 1980: 255; Bischof 2005: 74); se la emplea todavía bajo este nombre en el chiaraje o tinku (combate ritual) que se da anualmente en una pampa de Cusco (Arce Sotelo 2008:170). En Huarochirí (en la Sierra, entre Rímac y Lurín), en una sepultura colectiva al parecer "post-colonial”, Hrdlička (1914: 12) ha encontrado "un 'liburi' o 'bola', una boleadora con tres bolas irregulares y más bien pequeñas pero de metal pesado, arma muy similar a aquellas usadas por los Patagónicos", lo cual nos recuerda que en el manuscrito quechua de principios del siglo XVIII que 
narra los Ritos y tradiciones de Huarochirí (Taylor 1980: 69), se lee que los cinco pariacacas [dios tutelar de Huarochirí y sus cuatro hermanos] luchan contra su enemigo Hualallo Carhuincho, lanzando rihui, descritas como el arma empleada por los cazadores, que consistía en tres sogas de nervio de animal en cuyos extremos se amarraban pedazos de plomo.

Las boleadoras (de una a tres bolas) aparecen luego probablemente en los Andes centrales únicamente con los Collas del lago Titicaca, quienes la habrían encontrado entre los coyas que vivían en el altiplano al sur del Collasuyu, mientras que habrían sido adoptadas por el Inca Túpac Yupanqui y Huayna Cápac, quienes las valoraban de forma notoria como deporte y arma de combate (Hernández 2002: 153). Según Fr. Martín de Murúa (1590 [1962] I cap. 54: 161001), ésta sería el arma predilecta de los Collas, adoptada luego por los Incas; describe su uso en los ejércitos de Huáscar en la batalla de Cotabamba: "Y con unos instrumentos con que enlazan los benados, que tienen unas pelotas de plomo, tiraron a gran prieza a los que llevaban las andas, y dándoles en las piernas cayeron, dando con Huáscar en tierra". Se trataría luego de un proceso de adopción por los Collas -y luego por los Incas- de un arma de caza, con la finalidad de enfrentar la enorme ventaja táctica de la caballería española. Según Bischof (2005: 74), es un "arma de caza que en la época de la Conquista se usó contra los caballos".

Una variante era la 'bola perdida' (Salas 1950: 82-83; Hernández 2002: 123) o 'Wichi Wichi' en quechua, arma arrojadiza de una sola soga terminada por una piedra también llamada 'apaycha', y todavía utilizada en la provincia de Canas durante los combates rituales llamados 'chiaraje' (Alencastre y Dumézil 1953; Arce Sotelo 2008: 172).

\section{Cerbatanas}

Con la cerbatana, el cazador lanza una flecha muy ligera y corta, (dart en inglés). Generalmente elaborada a partir de un tubo de bambú, su alcance útil es de 30 a $40 \mathrm{~m}$. Arma tradicionalmente utilizada por los cazadores del bosque tropical húmedo hasta el día de hoy (Métraux 1963: 249) por su discreción (el tirador no hace ningún movimiento) y la posibilidad de emplearla en medio de una vegetación densa, es exclusivamente empleada como arma de caza y no de guerra en numerosos países, sobre todo en América del Sur y en el Caribe.

Los primeros testimonios arqueológicos irrefutables de cerbatana se encuentran en tumbas Mochicas y Nascas, lo cual permite presuponer que ésta fue traída desde la selva con cuyas poblaciones existía seguramente algún contacto, pero no hay prueba alguna de que hayan tenido un uso distinto al de la cacería. El ejemplar del Peabody Museum de Harvard, encontrado cerca de Trujillo, mide aproximadamente 5,4 $\mathrm{m}$ de largo, mientras que los dardos que la acompañan tienen un largo de 7,5 cm (Métraux 1963: 249). En la iconografía Mochica, es difícil distinguir una cerbatana de una simple vara de madera o báculo. No obstante, la evidencia documental existe: cerbatanas son visibles en dos vasijas de Trujillo reproducidas por Yde (1948 nº 104 y lam. II, 3), de las cuales una es citada en un artículo de d'Harcourt y Nique (1934). En esta vasija Mochica, se ve un cazador (en modelado), escondido detrás de una cortina, soplando en su cerbatana para cazar dos pájaros pequeños ubicados en un árbol cercano; otros pájaros pequeños están colgados de su cintura. El otro ejemplo es una vasija pintada representada en Wassermann-San Blas (1938, fig. 473) y Sawyer et al. (1954), que muestra asimismo un cazador mochica resguardado detrás de un escudo, apuntando con su cerbatana a tres pájaros posados en las ramas de un árbol. Larco Hoyle (1946: 163 lam. 31) lo describe de la siguiente manera: "la cerbatana y el propulsor para [cazar los] pájaros tales como las palomas y los patos salvajes". Coelho Penteado (1972: 38-40), quien ha estudiado tumbas Nasca en el sitio de Chaviña, habría también encontrado cerbatanas: "Es seguro que se encuentran hondas en las tumbas y las representaciones iconográficas, así como cerbatanas, flechas, aunque no es seguro que se trate de armas de guerra; podrían ser utilizadas para la caza".

Según Métraux (1963: 249), se encontró, asimismo, una representación de cerbatana en una tela de Pachacamac con fecha del periodo Intermedio Temprano. 
Entre los Incas, ningún cronista ni historiador de la guerra parece evocar la cerbatana, y de hecho su nombre tampoco aparece en los diccionarios quechua de Holguín (1608) o aymara de Bertonio (1612). No hemos encontrado mención alguna de la cerbatana en el ejército inca, lo cual permite presuponer que ni siquiera era usada aquí, inclusive entre los contingentes venidos de la Amazonía.

\section{SÍNTESIS Y CONCLUSIONES}

¿Qué conclusiones podemos sacar al término de esta síntesis sobre las armas arrojadizas a lo largo de la historia precolombina de los Andes centrales?

1. Existe una primera distinción funcional entre armas de caza y armas de guerra. Algunas armas arrojadizas parecen ser casi exclusivamente utilizadas para la caza, tal como el propulsor y la cerbatana. Otras, exclusivamente destinadas a la caza durante milenios, cambian de uso de forma tardía: la honda parece ser reservada a la caza hasta el final del Horizonte Temprano, mientras que la boleadora no se convierte en arma de guerra sino recién en la época inca (y quizás con sus antecesores inmediatos). El arco había quizás sido utilizado entre los cazadores de la puna, pero su uso como arma de guerra no es atestiguado hasta antes del Horizonte Medio. Las piedras redondas y las puntas talladas bajo la forma de armazones de armas arrojadizas aparecen en todas las épocas, y sirven tanto para la caza como para la guerra, aunque, al igual que el propulsor, la honda y el venablo, no son empleadas como armas de guerra sino de forma tardía. Las puntas de piedras pulidas que aparecen en las numerosas fortalezas entre el fin del Horizonte Temprano y el inicio del Intermedio Temprano son usadas como armas de guerra, aunque quizás como parte de armas de choque (puñales y lanzas).

2. Una segunda distinción, de orden funcional también, puede ser planteada entre armas y herramientas: así, el hacha es primeramente una herramienta antes de ser un arma. Las hachas de piedra pulida del Precerámico sirvieron en primer lugar para tallar estacas antes de ser usadas como armas. Las puntas de piedra y los puñales o cuchillos son herramientas de uso común. Asimismo, las piedras redondas de cierto peso han sido a menudo utilizadas como chancadores, tal como lo demuestran las huellas de uso (Brown Vega 2008 : 329) o como pulidor o bruñidor (Lau 2001 : 393 , 394 y fig.11.12,11.13). En cambio, las demás armas arrojadizas no pueden ser usadas a manera de herramientas de trabajo.

3. En definitiva, el punta capital que sobresale de nuestro estudio es que las armas arrojadizas eran poco utilizadas para la guerra antes de los incas, lo cual puede significar una preferencia por el combate cuerpo a cuerpo, con armas de estoque, como lo advertiremos en un próximo articulo sobre las armas de choque.

4. Hemos resumido en la Tabla 6 los periodos de presencia de las diferentes armas de caza o de guerra y/o de instrumentos. Como se puede ver, algunas armas aparecen momentáneamente, antes de desaparecer luego. Éste es el caso del propulsor, el cual se presenta al final del Precerámico y desaparece prácticamente hasta la mitad del periodo Intermedio Temprano en el norte (Mochica), mientras que perdura en la Costa sur (Paracas y Nasca), y parece ser un signo de estatus nada más entre los incas, como lo subrayan Uhle y todos los cronistas. Es también el caso de la honda, cuyo uso es atestiguado en el Precerámico, pero que por lo visto desaparece en el Norte hasta el final del Horizonte Temprano, mientras que sigue siendo de uso común en la Costa sur (Paracas), y es luego omnipresente hasta la Conquista.

Una observación general derivada de lo que precede es un mayor conservadurismo en el empleo de armas en la Costa sur: propulsores, hondas, puntas de piedra tallada son constantemente empleadas; en el norte en cambio, se ve una movilidad mayor, con un uso adaptado más rápidamente a un medio cambiante y probablemente también a los aportes por parte de nuevas poblaciones. 
Tabla 6: Periodos de presencia de las diferentes armas de caza o de guerra y/o de instrumentos.

\begin{tabular}{|c|c|c|c|c|c|c|c|c|c|}
\hline pe & & 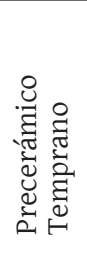 & 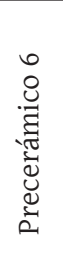 & 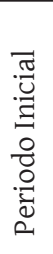 & 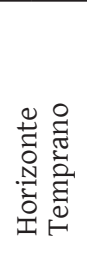 & 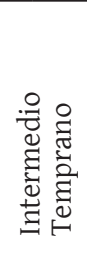 & 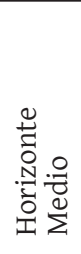 & 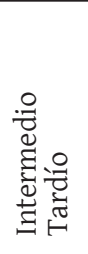 & 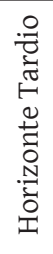 \\
\hline \multicolumn{10}{|l|}{ Proyectiles redondos } \\
\hline \multirow{2}{*}{ Honda } & $\mathrm{N}$ & & & & & & & & \\
\hline & $\mathrm{S}$ & & & & & & & & \\
\hline \multirow{2}{*}{ Propulsor } & $\mathrm{N}$ & & & & & & & & \\
\hline & $\mathrm{S}$ & & & & & & & & \\
\hline \multirow{2}{*}{ Punta tallada } & $\mathrm{N}$ & & & & & & & & \\
\hline & $\mathrm{S}$ & & & & & & & & \\
\hline \multicolumn{10}{|l|}{ Punta pulida } \\
\hline Boleadora & & & & & & $?$ & & & \\
\hline \multicolumn{10}{|l|}{ Arco } \\
\hline Cerbatana & & & & & & & & & \\
\hline
\end{tabular}

5. En último término, se podría postular una distinción entre uso real (herramienta, arma de caza o de guerra), y uso simbólico. Esa distinción es compleja y no depende solamente de la presencia/ ausencia en la iconografía o arqueología, pero sí en la contextualización de los dos. Esa distinción aparecerá más claramente con el conjunto de la armas de choque y armas arrojadizas.

En la tabla 7, tentamos de sintetizar esta distinción en la base de nuestra documentación por periodo y por área para las dos principales armas arrojizadas (propulsor y honda). La honda por ejemplo, es frecuentemente encontrada en las tumbas Paracas, pero nunca en la iconografía, lo cual significa que no jugaba un papel simbólico importante. De igual manera, si el propulsor es frecuente en la iconografía Mochica, pero que no se lo encuentra nunca en las tumbas, es porque tenía un papel en la caza ritual de venados (Fig. 4) (Donnan 1997; 1999: fig. 4.58). El motivo es quizás el mismo en el caso de la honda Mochica, que debió servir para la caza de aves. A la inversa, la honda aparece frecuentemente en las tumbas y la iconografía Nasca, lo cual podría indicar que su papel simbólico se incrementó entre los nascas.

Tabla 7: Uso de los dos principales tipos de armas.

\begin{tabular}{|c|c|c|c|c|c|}
\hline \multirow{2}{*}{\multicolumn{2}{|c|}{ Propulsor }} & \multicolumn{2}{|c|}{ Testimonio } & \multicolumn{2}{|r|}{ Uso } \\
\hline & & arqueológico & iconográfico & real & simbólico \\
\hline \multicolumn{2}{|c|}{ Preceramico 6} & caza (ver tabla 3) & & $\mathrm{X}$ & \\
\hline \multirow[t]{2}{*}{$\begin{array}{l}\text { P. Inicial+ } \\
\text { H.Tempr. }\end{array}$} & Costa norte & escaso (tabla 4) & $\begin{array}{l}\text { Escenas simbólicas } \\
\text { Señal de poder } \\
\text { (Burger 1987) }\end{array}$ & & $\mathrm{X}$ \\
\hline & sur (Paracas... & caza & caza & $\mathrm{X}$ & \\
\hline \multirow[t]{2}{*}{$\begin{array}{l}\text { Intermedio } \\
\text { Temprano. }\end{array}$} & $\begin{array}{l}\text { Costa norte (Vicús, } \\
\text { Moche... }\end{array}$ & En tumbas de elite & $\begin{array}{l}\text { Caza ritual } \\
\text { 'badmington' }\end{array}$ & & $\mathrm{X}$ \\
\hline & Costa sur (Nasca... & caza & caza & $\mathrm{X}$ & \\
\hline \multirow{2}{*}{$\begin{array}{l}\text { Horizonte. } \\
\text { Medio }\end{array}$} & costa & Caza y pesca & $?$ & $\mathrm{X}$ & \\
\hline & Sierra & ? & Señal de poder & & $\mathrm{X}$ \\
\hline \multicolumn{2}{|c|}{ Intermedio Tardío + } & & & & \\
\hline \multicolumn{2}{|c|}{ Horizonte Tardío (inca) } & $?$ & Señal de poder & & $\mathrm{X}$ \\
\hline
\end{tabular}


Vincent Chamussy / Empleo de armas arrojadizas en el área centro-andina

\begin{tabular}{|c|c|c|c|c|c|}
\hline \multirow{2}{*}{\multicolumn{2}{|c|}{ Hondas }} & \multicolumn{2}{|c|}{ Testimonio } & \multicolumn{2}{|c|}{ Uso } \\
\hline & & arqueológico & iconográfico & real & simbólico \\
\hline \multicolumn{2}{|c|}{ Precerámico 6} & caza & & $\mathrm{X}$ & \\
\hline \multirow[t]{2}{*}{ P. Inicial } & $\begin{array}{l}\text { Costa norte } \\
\text { (Cupisnique, } \\
\text { Chavín... }\end{array}$ & & & & \\
\hline & Sur (Paracas... & caza & & $\mathrm{X}$ & \\
\hline \multirow{2}{*}{$\begin{array}{l}\text { Horizonte } \\
\text { Temprano }\end{array}$} & $\begin{array}{l}\text { Costa norte } \\
\text { (Santa-Huaura) }\end{array}$ & $\begin{array}{l}\text { Guerra (fin del } \\
\text { Periodo }\end{array}$ & escaso & $\mathrm{X}$ & \\
\hline & Sur (Paracas..; & caza & & $\mathrm{X}$ & \\
\hline \multirow[b]{2}{*}{$\begin{array}{l}\text { Intermedio } \\
\text { Temprano }\end{array}$} & Norte (Moche... & & & & \\
\hline & Sur (Nasca... & $\begin{array}{l}\text { Caza (ritual } \\
\text { Yacovleff y Muelle } \\
1974\end{array}$ & caza & & $\mathrm{X}$ \\
\hline \multicolumn{2}{|c|}{ Horizonte Medio } & guerra & & $\mathrm{X}$ & \\
\hline \multicolumn{2}{|c|}{$\begin{array}{l}\text { Intermedio Tardío + } \\
\text { Horizonte Tardío (inca) }\end{array}$} & guerra & $\begin{array}{l}\text { Ilapa, símbolo de } \\
\text { poder }\end{array}$ & $\mathrm{X}$ & $\mathrm{x}$ \\
\hline
\end{tabular}

\section{Agradecimientos}

Agradezco a mis amigos universitarios que me ayudaron en mis trabajos tanto en Francia: Eric Taladoire, Patrice Lecoq, Nicolas Goepfert y Catherine Lara quien se encargo de la traducción, así como en Perú: Prof. Segundo Vasquéz, Peter Kaulicke y Iván Ghezzi. Asimismo expreso un agradecimiento especial al corrector y al editor de la revista quienes han formulado muchas sugerencias particularmente útiles. Agradezco también a los habitantes de los valles del centro-norte y especialmente Ian Mezzich de Chimbote.

\section{BiBLIOGRAFÍA}

ALDENDERFER, Mark

2005 "Preludes to power in the highland Late Preceramic period". En: Kevin J. Vaughn, Dennis Ogburn, y Christina A. Conlee (eds.), Foundations of power in the prehispanic Andes, Archeological Papers of the American Anthropological Association Number 14: 14-35 01/10.

ALENCASTRE, Andrés y Georges DUMEZIL

1953 "Fêtes et usages des Indiens de Langui". Journal de la Société des Américanistes ns. TXLII: 1-118.

ALVA, Walter

2001 "The royal tombs of Sipan: Art and power in Moche society". En: Moche art and archaeology in Ancient Peru, Joanne Pillsbury ed. National Gallery of Art, Washington, distributed by Yale University Press, New Haven \& London.

2007 Sipan. Descubrimento e investigación. Q.W. Editores S.A.C, Lima BP.

2008 "Las tumbas reales de Sipán". En: Makowski, K. (ed.), Señores de los reinos de la luna Banco de Crédito del Perú, Lima: 266-279.

ALVA, Walter y Christopher DONNAN

1993 Royal tumbs of Sipán, Fowler Museum of Cultural History, University of California, Los Angeles.

ÁNGELES, Rommel y Denise POZZI-ESCOT

2010 "El Horizonte Medio en Pachacamac". En: Rubén Romero Velarde y Trine Pavel Svendsen (eds.), Arqueologia en el Perú. Nuevos aportes para el estudio de las sociedades andinas prehispánicas: 173-196.

ARCE SOTELO, Manuel

2008 "Batallas rituales, juegos rituales: el componente Pullay en el chiaje y otras manifestaciones andinas". Perspectivas latino americanas, $\mathrm{n}^{\circ} 5$, Centro para el estudio de la Universidad de Nanzan, Nagoya, Japón. 
ARRIAZA, Bernardo T., Vivien G. STANDEN, Vicki CASSMAN y Calogero SANTORO

2008 "Chinchorro cultures: Pionners of the cost of the Atacama desert". En: Handbook of South American Archaeology, Helaine Silverman y William H. Isbell (eds.), Springer, New York.

AVILA, Francisco (de)

1598 Dioses y hombres de Huarochiri. Naracción quechua recogida por Francisco de Avila [ed. 1999]: Gerald Taylor (traducción) Ritos y tradiciones de Huarochiri. $2^{a}$ ed. révisada. Travaux de l'Institut Français d'Etudes Andines t. 116 Lima.

BANKES, Georges H.A.

1977 Perú before Pizarro. Oxford: Phaidon Press.

BAWDEN, Garth L.

1982 "Galindo: a study in cultural transition during the Middle Horizon in northerncoastal Peru". En: M.E. Moseley and K.C.Day (eds.) Chanchan, Andean Desert City: 285-320; Albuquerque: University New Mexico Press.

BENFER, Robert A.

2010 Definición de la astronomia temprana del sitio de Buena Vista, Proyecto de Investigación arqueológica, informe final al INC.

BERTONIO, Ludóvico P.

1984 [1612] Vocabulario de la lengva aymara, ed. CERES, La Paz, Bolivia, Instituto Francés de Estudios Andinos, collección "Travaux de l'IFEA” tomo XXVI.

BETANZOS, Juan Diez (de)

1968 [1551] Suma y narracion de los Incas. Biblioteca de Autores Españoles, tomo 209 (Cronicas Peruanas de Interes Indigena): 1-56, Madrid: Ediciones Atlas.

BIRD, Junius

1948 "Preceramic cultures in Chicama and Virú". En: Wendell C. Bennett (ed.), A reappraisal of peruvian archaelogy. Memoirs of the society of american archaelogy 13 (4) :21-28.

BISCHOF, Henning

2005 "Violencia y guerra en los Andes centrales a través de las fuentes arqueológicas". En: Peter Eeckhout y Geneviève Le Fort (eds.) Wars and conflicts in prehispanic Mesoamerica and the Andes, BAR International Series 1385: 66-89.

BLITZ, J.H.

1988 "Adoption of the bow in prehistoric North America". North American Archaeology, vol. 9 (2): 123-145.

BONAVIA, Duccio

1991 Perú. Hombre e historia. Lima: Edubanco.

1994 Arte e historia del Perú antiguo. Colleccion Enrico Poli, Bianchi, Lima: Banco del Sur.

BOAS, Franck

1938 General anthropology. Boston: DC Heath and Company.

BOURGET, Steve

2001 "Rituals of sacrifice: Its practice at Huaca de la Luna and its representation". En: Moche iconography, in Moche society. In Joanne Pillsbury (ed.), Moche art and archaeology in Ancient Peru, National Gallery of Art, Washington, distributed by Yale University Press, New Haven and London: 89-109.

2006 Sex, death and sacrifice in Moche religion and visual culture, University of Texas Press, Austin.

BRENNAN, CurtissT.

1978 Investigations at Cerro Arena, Peru; incipient urbanism on the North Coast of Peru. Unpublished Ph.D. Dissertation, University of Arizona, Tucson.

1980 "Cerro Arena: Early cultural complexity and nucleation in North Coastal Peru". Journal of Field Archaeology 7: 1-22.

1982 "Cerro Arena: Origins of the urban tradition on the peruvian North Coast". Current Anthropology 23 (3) :247-254.

BROWN VEGA, Margaret

2008 War and social life in prehispanic Perú: Ritual, defense, and ommunities at the fortress of Acaray, Huaura Valley. Ph. D. Dissertation, University at Illinois at Urbana Champaign. 
2010 "Regional patterns of fortification and single forts: Evaluating the articulation of regional sociopolitical dynamics with localized phenomena". En: R. Cutright, E. Lopez-Hurtado, and A. Martin (eds) Comparative perspectives on the archaeology of Coastal South America, Pittsburgh: University of Pittsburgh Center for Comparative Archaeology, PUCP (Lima), Ministerio de Cultura de Ecuador (Quito).

BROWN VEGA, Margaret y Nathan CRAIG

2009 "New Experimental data on the distance of sling projectiles". Journal of Archaeological Science,36 (6):1264-1268.

BURGER, Richard L.

1982 "Pojoc and Waman Wain: two Early Horizon villages in the Chavín heartland". Ñawpa Pacha 20: $3-40$.

1985 "Prehistoric stylistic change and cultural development at Huaricoto, Peru". National Geographic Research, vol.1, n² : 505-534.

1988 "Unity and heterogeneity within the Chavín horizon”. En: Richard W. Keatinge (ed.), Peruvian prehistory, Cambridge University Press.

1992 Chavin and the origins of Andean civilization. New York: Thames and Hudson.

2003 "Cambios estilisticos y desarrollo cultural en Huaricoto". En: Bebel Ibarra Asencios (ed.) Arqueología en la sierra de Ancash: 18-50.

BURGER, Richard L. y Michael D. GLASCOCK

2009 "Intercambio prehistórico de obsidiana a larga distancia en el norte del Perú". Revista del Museo de Arqueología, Anthropología e Historia, n 11 Universidad National de Trujillo: 17-50.

BUSHNELL, Geoffroy Hext Sutherland

1965 Ancient art of the Americas. Neew York: Thames and Hudson.

CÁRDENAS MARTIN, Mercedes

1969 "Presencia de concha y hueso en el antiguo Perú". Boletín del Seminarío de Arqueologia. PUCP, Instituto Riva-Agüero. n²: 46-6.

CARDICH, Augusto

1958 "Los Yacimientos de Lauricocha. Nuevas interpretaciones de la prehistoria peruana". Acta Prehistorica II Centro Argentino de Estudios Prehistoricos: 35-48 Buenos Aires.

1964 "Lauricocha. Fundamentos para una prehistoria de los Andes centrales". Studia Praehistorica III,Centro Argentino de Estudios Prehistoricos. Buenos Aires.

CARRIÓN CACHOT de Gerard, Rebeca

1949 Paracas, cultural elements. Corporación General del Turismo.

CARRIÓN ORDÓNEZ, Enrique,

1997 "Un enigma etimologico: Estolica". Lex, PUCP, 21 (1): 139-143.

CASAS, Bartolomé (de las)

1892 [1550] De las Antiguas gentes del Peru, por el padre Fray Bartolomé de la Casas (Prologo de M. Jimenez de La Espada); Coleccion de Libros Españoles raros o curíosos. Tomo vigesimoprimero-Madrid.

CHAMUSSY, Vincent

2009 Les débuts de la guerre institutionnalisée dans l'Aire Andine Centrale: vers la formation de l'Etat, du Formatifà la Période Intermédiaire Ancienne (2000 a.C.-500 d.C), BAR International Series 2017, Oxford, England.

CHAPDELAINE, Claude y Victor PIMENTEL

2002 "La presencia Moche en el valle del Santa, Costa norte del Perú". Informe del Proyecto Arqueologico PSUM (Proyecto Santa de la Universidad de Montreal) Mayo-Agosto 2001.

CHAPDELAINE, Claude, Victor PIMENTEL y Jorge GAMBOA

2009 "Gallinazo. Architecture, burial patterns, and sociopolitical organization". En: Jean François Millaire with Magamo Morlion (eds.), Gallinazo. An early cultural tradition on the peruvian North Coast: 181-206, UCLA Cotsen Institute ofArchaeology Press.

CHAUCHAT, Claude

1992 Préhistoire de la côte nord du Pérou: le Paijanais de Cupisnique, CNRS- éditions. Bordeaux (« cahiers du Quaternaire »). 
CHICOINE, David y Hugo IKEHARA,

2008 "Nuevas evidencias sobre el Periodo Formativo del valle de Nepeña: Resultados preliminares de la primera temporada de investigaciones en Caylán”. Boletín de Arqueología PUCP nº 12: 349-369.

COBO Fray Barnabé

1964 [1653] Historia del Nuevo Mundo, BAE, Madrid

CLASTRES, Pierre

1977 Archéologie de la violence : la guerre dans les sociétés primitives, édition de l'Aube

COELHO Vera Penteado

1972 Enterramentos de cabeças da cultura Nasca. Tesis de doctorado apresentada ao depto. de Communicaçoes e Artes da USPE (mimeo) Sao Paulo.

COHEN Mark N.

1978 "Population pressure and the origins or agriculture: An archaeological example from the Coast of Peru". En: Advances in Andean Archaeology, David L. Browman (ed.) Mouton, La Haye, Paris.

CORDIER, G

1990 "Blessures préhistoriques animales et humaines avec armes ou projectiles conservés". Bulletin de la Société Préhistorique Française 87: 462-481.

DAGGETT, Richard E.

1984 The early occupation of the Nepeña valley, North Central Coast of Peru, PH. D. dissertation, University of Massachussets, Amherst. Ann Harbor.

D'ALTROY, Terence N.

2008 The Incas. People of America, Blackwell Publishers. Malden, Oxford.

DE LEONARDIS, Lisa

2000 "The Body context: Interpreting early Nasca decapited burials". Latin AmericanAntiquity 11: 363-386.

DE LEONARDIS, Lisa y George F. LAU

2004 "Life, death, and ancestors". En: Helaine Silverman (ed.) Andean Archaeology, Blackwell Publishing: 76-115.

DE MORTILLET, Gabriel

1910 "Le propulseur à crochet chez les Anciens Péruviens". L'Homme Préhistorique 1910: 235-243.

DENNELL, Robin

1997 “The world's oldest spears". Nature 385: 767-768.

DEZA RIVASPLATA, Jaime

1978 "El excedente en la economia marina del Arcaico Tardío". En Ramiro Matos (ed.) III Congreso Peruano: El Hombre y la Cultura Andina, Actas y Trabajos (31 de Enero-5 de Febrero 1977, tomo 1, 251-257 Lima.

DILLEHAY, Thomas D.

2000 The settlement of the americas. A new prehistory, Basic Books, New york.

DILLEHAY, Tom D., Duccio BONAVIA y Peter KAULICKE

2004 “The First settlers". En: H. Silverman (ed.), Andean Archaeology: 16-34. Blackwell, Malden, MA.

DONNAN, Christopher B.

1978 Moche art of Peru, Museum of Cultural History, University of California, Los Angeles.

1992 Ceramics of ancient Peru, University of California, Los Angeles, Fowler Museum of Cultural History.

1997 "Deer hunting and combat: Arallel activitie in Moche World". En: Katheen Berrin (ed.), The Spirit of Ancient Peru, Thames and Hudson and the Modern Art Museum of San Francisco

2003 "Tumbas con entierros en miniatura: un nuevo tipo funenarío moche". En: Uceda Santiago y Elias Mujica (eds), Moche, hacia el final del Milenio, colloquio 1999, t. 1: 43-78, PUCP y Universidad Nacional de Trujillo.

1993 Royal tombs of Sipan, Fowler Museum of Cultural History, University of California, Los Angeles

DONNAN, Christopher B. and Donna McCLLELAND

1979 "The burial theme in Moche iconography". Studies in Pre-columbian art \& archaeology 21, Dumbarton Oaks Trustees for Harvard University Washington, D.C

1999 Moche fineline painting: Its evolution and its artists. UCLA Fowler Museum of Cultural History, Los Angeles. 
DONNAN, Christopher B. y Guillermo COOK (eds.),

1986 The Pacarnamú papers. Vol I, Los Angeles: Museum of Culture History, University of California.

1997 The Pacatnamú papers, Vol. II. Los Angeles: Fowler Museum of Cultural History.

EISLEB, Dieter

1977 Altperuanische kulturen II, Nasca, Museum für Völkerkunde, Berlin.

ELERA, Carlos

1992 "Arquitectura y otras manifestaciones culturales del sitio Formativo del Morro de Eten. Un enfoque preliminar". En: Ducio Bonavia (ed.), Estudios de arqueología peruana: 177-192, colloquio FOMCIENCIAS, 1/1988.

1998 The Puemape site and the Cupisnique culture: A case study on the origins and development of complex society in the Central Andes, Peru, Dissertation for the degree of Doctor of Philosophy, dept of Archaeology, Calgary, Alberta.

ENGEL, Frédéric

1956 "Curayucu-a Chavínoïd site". Archaeology 9 (2): 98-105.

1957 "Early sites on the peruvian cost". Southwestern Journal of Anthropology 13: 54-68.

1958 "Algunos datos con referencia a los sitios precerámicos de la costa peruana". Arqueológicas, 3. Museo Nacional de Anthropología y Arqueología, Lima.

1960 "Un groupe humain datant de 5000 ans à Paracas, Pérou". Journal de la Société des Américanistes, n 49: 7-36.

1963a "Notes relatives a des explorations archéologiques à Paracas et sur la côte sud du Pérou". Travaux de l'IFEA Paris-Lima.

1963b A Preceramic settlement on the central Coast of Peru: Asia, Unit 1, Transactions of the American Philosophical society, 53 (part 3) .pp 3-139, Philadelphia.

1966 Geografia humana prehistórica y agricultura precolombina de la quebrada de Chilca, Universidad Agraria, Lima.

1972 Le Monde précolombien des Andes, Hachette, Paris.

1976 An ancient world preserved. Relics and records of prehistory in the Andes, Crown, New york.

1988 Ecologia prehistórica andina; vol. 1 Chilca, Pueblo 1; Implementos de Huesos, Centro de Investigaciones de Zonas Aridas. Lima, Perú.

1991 Un desierto en tiempos prehispanicos, río Pisco, Paracas, río Ica, Perú.

FERIZ, Hans

1958 Demonstration of a south-Peruvian arrow throwing-stick. Proceedings of the Thirty Second International Congress of Americanists: 441-444, Munksgaard, Copenhagen.

FERRIL, Arther

1997 The origins of war, from the stone age to Alexander the Great, Bourlder (co) Osford Westview press.

FRANCO JORDÁN G.

2009 Mochica, Los secretos de la Huaca Cao Viejo, Colección Perú Milenario, Fundación Wiese.

FRANCO JORDÁN, Regulo G., Cesar GALVEZ MORA A y Segundo VASQUEZ SANCHÉZ

2001 "La Huaca Cao Viejo en el complejo El Brujo: una contribución al estudio de los Mochicas en el valle de Chicama". Arqueológicas № 25.

FUNG PINEDA, Rosa

1969 "Los anzuelos de concha de Las Aldas: Un analisis comparativo". Boletín del Seminarío de Arqueología $n^{\circ} 4$ : 29-43, Instituto Riva Aguero, PUCP, Lima.

FUNG PINEDA, Rosa y Carlos WILLIAMS

1977 “Exploraciones y Excavaciones en el valle de Sechín, Casma”. Revista del Museo Nacional ,43 (1977): 111-155.

GALVEZ MORA, Cesar y Carlos QUIROZ MORENO

2008 "En torno a la hipotesis del uso de puntas de proyectil para capturar peces en el Paijanense (ca. 11.000 ap)". Archaeobios, sept. 2008, n² vol 2.

GARCILASO DE LA VEGA

1982 [1609] Comentarios reales de los Incas, F. Maspero (ed.), coll FM/Découvertes, Paris, 3 tomos. 
GERO, Joan M.

1983 Material culture and the reproduction of social complexity: a lithic example from the peruvian Formative. $\mathrm{PhD}$. Dissertation, University of Massachusets.

GHEZZI, Iván

2006 "Religious warfare at Chankillo". En: William ISBELL and Helaine SILVERMAN ,(eds.) Andean Archaeology 3, Springer: 67-84.

2008 "Los Primeros tambores de la guerra". En: Krzystof Makowski (ed.), Señores de los reinos de la Luna: 38-53, Colección Arte y Tesoros del Perú, Lima/ Banco de Crédito.

GONZÁLES HOLGUIN, Diego

1608 Vocabulario de la lengua general de todo el Perú llamada lengua Qquichua, o del Inca, corregido y renovado conforme a la propiedad cortesana del Cuzco. (Lima), edición original, Universidad de Santiago de Chile.

GUAMAN POMA de AYALA, Felipe

1980 [1613] Nueva corónica y buen gobierno, ed. fac-similé, Paris 1936; y edición crítica de John Murra y Rolena Adorno, Siglo XXI, Mexico DF.

GUFFROY, Jean

1999 El arte rupestre del Antiguo Peru, Série Travaux de l'Institut Français d'Etudes Andines, t.112.

GUILAINE, Jean y Jean ZAMMIT

2001 Le sentier de la guerre, visages de la violence préhistorique. Le Seuil, Paris.

GUILLÉN, Sonia y Gerardo CARPIO,

1999 Violencia en el desierto: un entierro arcaico en el sitio de Villa del Mar-IPS, Ilo, Boletín de Arqueología PUCP n 3: 365-373

HAAS, Jonathan

2001 "Warfare and the evolution of culture". In G.M. Feinman and T.D. Price (eds.) Archaeology at the millenium: A Sourcebook: 329-350, New York: KluwerAcademic Publishers

HARCOURT (d'), Raoul y Jeanne NIQUE

1934 "La sarbacane, l'élevage des oiseaux, la tête réduite chez les peuples mochicas". Journal de la Société des Américanistes, vol 26: 103-108.

HEIZER, Robert F. y Irmgard W. JOHNSON

1952 "A prehistoric sling from Lovelock Cave, Nevada". American Antiquity 18 (1): 139-147.

HEMMING, John

1971 La conquête des Incas, Stock, Témoins de tous les temps, Paris.

HERNÁNDEZ, Jesús Vega

2002 "Hondas y boleadoras en la América hispana". Anales del Museo de América 10: 113-136, Madrid.

HUAPAYA MANCO, Cirilo

1978 “Asentamiento sin cerámica en Illescas-Piura". En: Ramiro Matos (ed.), III Congreso Peruano: El Hombre y la Cultura Andina, Actas y Trabajos (31 de Enero-5 de Febrero 1977, tomo I, 257-272, Lima.

IZUMI, Seiichi and Toshihico SONO

1963 Excavations at Kotosh, Peru, 1960, Andes 2, Tokyo: Kadokawa Publishing

IZUMI, Seiichi and Kazuo TERADA

1972 Excavations at Kotosh, Peru, 1963 and 1966. Andes 4, University Tokyo.

HOCQUENGHEM, Anne Marie

1979 "L'iconographie Mochica et les rites de purification". Baessler Archiv vol. 27: 215-252.

1987 Iconografia mochica. PUCP, Fondo Editorial, Lima.

HOFFECKER, John F

2005 "Innovation and technological knowledge in the upper Paleolithic of Northern Eurasia". Evolutionnary Anthropology 14 (5): 186-198.

HOSTNIG, Rainer

2003 "Macusani y Corani, repositorios de arte rupestre milenario en la cordillera de Carabaya, Puno, Perú". Boletín No. 17 (2003) de la SIARB (Cusco) 12/10.

2007 El arte rupestre de Carabaya, Empresa de Generación Electríca San Gabán. 
HRDLIČKA Aleš

1914 Anthropological work in Peru, in 1913, with notes on the pathology of the ancien peruvians, with twenty six plates. Smithsonian Miscellaneous Collections, vol 16, $\mathrm{n}^{\circ}$. 18, Washington, D.C. Smithsonian Institution.Catalogue de l'exposition de Bruxelles (Musées Royaux d'Art et d'Histoire)

1990 Inca Pérou, 3000 ans d'Histoire. Civilisations Précolombiennes au Pérou.

ISBELL, William

2001 “Wari, un imperío por definir". En: Fundación El Monte (ed.), Wari, Arte Precolombiano Peruano. Catalogo de exposición, Sevilla, enero-marzo 2001: 99-173.

ISBELL, Willimam H. y Patricia J. KNOBLOCH

2006 "Missing links, imagery links: Staff god imagery in the South Andean Past". En: William Isbell y Helaine Silverman (eds), Andean Archaeology III, North and South, Springer, USA: 307-351.

IZUMI, Seiichi. and Toshihico SONO

1963 Excavations at Kotosh, Peru, 1960. Andes 2. Tokyo : Kadokawa Publishing

IZUMI, Seiichi and Kazuo, TERADA (eds.)

1972 Excavations at Kotosh, Peru, 1963 and 1966. Andes 4, University Tokyo Press

JEREZ, Francisco (de)

1946 [1534] Crónica de la conquista del Perú, rev. y anot. por le rev. Brusone, Julio J. Mexico: Editorial Nueva Espana

KEELEY, L. H., M. FONTANA y R. QUICK

2007 "Baffles and bastions: the universal features of fortifications". Journal of Archaeological Research 15:55-95

KLINK, Cynthia y Mark ALDENDERFER

2005 "A projectile point chronology for the South-Central Andean highlands". En: Charles Stanish, Armanda B. Cohen and Mark S. Aldenderfer (eds.), Advances in the Titicaca Basin Archaeology 1, Cotsen Institute of Archaeology, University of California, Los Angeles: 25-54.

KORFMAN, Manfred

1973 "Sling as a weapon". Scientific American 229 (4): 34-42.

KROEBER, Alfred L. and Donald COLLIER

1998 "The archaeology and pottery of Nazca, Peru". En: Alfred L. Kroeber's 1926 expedition; Patrick Carmichael (ed.), Altamira Press, Walnut Creek.

KUTSCHER, Gert

1958 "Ceremonial badminton in Moche". Proceedings of the XXXIII International Congress of Americanists, Copenhagen, 1956.

1967 "Iconographic studies as an aid in the reconstruction or Early Chimu civilization". En:J. H. Rowe and D. Menzel (eds.), Peruvian Archaeology: Selected Readings ed: 115-124, Palo Alto: Peek Publications.

1983 "Nordperuanische Gefässmalereien des Moche-Stils". Introducido y documentado por Ulf Bankman, Materiallen sur Allgemeinen und Vergleichenden Archäologie, Band 18, Verlag C. H. Beck, München.

LAMBERT, Patricia A.

2007 "The osteological evidence for indigenous warfare in North America". North American indigenous warfare and ritual violence, Richard J. Chacon and Rubén G. Mendoza, The University of Arizona Press, Tucson: 202-222.

LANNING, Edward P

1967 Peru before the Incas, Englewood Cliffs, N.J./ Prentice Hall.

LAPINER, Alan

1976 Precolumbian art of South America. Harry N. Abrams, New York.

LARCO HOYLE, Rafael

1945 La cultura Virú, monographie.

1946 "A cultural sequence for the North Coast of Peru". En: Handbook of South American Indians (Julien H., Steewart, ed.) Smithsonian Institution. Bureau of American Ethnology, Bulletin 143 (2): 149-175. Washington D.C.

2001 Los Mochicas, tomo 1et 2, reédición por Museo Arqueológico Rafael Larco Herrera. 
LAU, Georges, Fu Yan

2001 The ancient community of Chinchawas: Economy and ceremony in the North highlands of Peru. Ph. D. Dissertation, Yale University.

2004 Objects of contention: An examination of Recuay-Moche combat imagery. Cambridge Archaeological Journal vol $14 \mathrm{n}^{\circ} 2$ oct 2004.

2010a "Fortifications as warfare culture: The hilltop centre of Yayno (Ancash, Peru) , AD 400-800". Cambridge Archaeological Journal 203: 419-448.

$2010 \mathrm{~b}$ "House forms and Recuay culture: Residential compounds at Yayno (Ancash, Peru). A fortified hilltop town, AD 400-800". Journal of Anthropological Archaeology 29: 327-351.

LAVALLE, José Antonio (de) (ed)

1984 Moche. Collección arte y tesoros del Perú. Banco de Credito del Peru en la Cultura, Lima.

1989 Culturas precolombinas: Nazca. Collección Arte y tesoros del Perú, Banco de Credito del Perú en la Cultura, Lima ( $2^{\circ}$ ed.),

LAVALLÉE, Danielle

1969 "Industrias liticas del período Huaraz, procedentes de Chavín de Huántar". En: Revista del Museo Nacional, Tomo XXXVI: 193-23.

1977 “Telarmachay, campamento de pastores en la puna de Junín del Período Formativo". Revista del Museo Nacional XLIII: 63-109.

1985 Telarmachay, chasseurs et pasteurs préhistoriques des Andes ADPF-ERC, Paris.

1995 Promesse d'Amérique, la Préhistoire de l'Amérique du Sud, Hachette, collection La mémoire du Temps.

LEGOUPIL, Dominique

2003 2L'utilisation de la pierre naturelle, polie et piquetée". En: Dominique Legoupil (ed.), Les chasseurscueilleurs de Ponsonby (Patagonie Australe) et leur environnement du VI au III millénaire BC, Univ. de Magallanes, Punta Arenas (Chile).

LEGOUPIL, Dominique y Nicole PIGEOT

2009 "Les grandes pointes foliacées de type Ponsonby. Un traceur culturel en Patagonie Australe". Journal de la Société des Américanistes t. 95-2.

LEROI-GOURHAN, André

1964 Le geste et la parole (II- La mémoire et les rythmes) Albin Michel.

1973 L'homme et la matière (Milieu et Technique), Albin Michel, Paris.

1997 Dictionnaire de la Préhistoire, Presses Universitaires de France, col. Quadrige, Paris.

LLANOS JACINTO, Óscar Daniel

2009 Le bassin du río Grande de Nazca, Pérou, Archéologie d'un État Andin 200 av. J.-C.-650 ap. J.-C., BAR International Series 1990.

LÓPEZ MENDOZA, Víctor

1980 "El Ejército Incaico, interpretacion contemporanea". En: Historia general del exercito peruano, Guilen Guilen Edmundo y Victor Lopez Mendoza (eds.), tomo II; 271-406.

LOTHROP, Samuel K. y Joy MALHER

1957 Late Nazca burials at Chaviña, Peru. Papers from the Peabody Museum of Archaeology and Ethnology, vol 50, $n^{\circ} 2$ Peabody Museum of Archaeology, Cambridge, Massachussets.

LUJÁN, Milton

2010 "Religión, culto, poder y muerte: vínculos de ritualidad y sacrificio en el edificio escalonado de Cerro Salazar (Mala) a fines del periodo Intermedio Temprano". En: Rubén Romero Velarde, y Ttrine Pavel Svendsen (eds.), Arqueología en el Perú, nuevos aportes para el estudio dee las sociedades andinas prehispánicas: 105-130. Lima: Anheb Impressiones.

LUMBRERAS, Luis Guillermo

1980 “Los origines de la guerra y el ejercito en el Perú". En: L.C. Vellarde y L. G. Lumbreras (eds). Historia general del Ejército peruano.

MACNEISH, Richard. S. et al.

1980 Prehistory of the Ayacucho Basin, Peru (4 vol). R.S. Peabody Foundation for Arcchaelogy, University of Michigan Press, Ann Harbor

1980 Guitarerro cave. Early man in the Andes. New York Academic press. 
MAKOWSKI, Krzysztof

2001 “Los personages frontales de báculos en la iconografía Tiahuanaco y Huari: ¿Tema o convención?". Boletín de Arqueología PUCP n 5: 337-373.

2002 "El manto de Gotenburgo y los calendaríos prehispanicos". El hombre y los Andes 2002, t. 1: 469-496, séminaire Paris IV, février 2004.

2003 "La imagen de la sociedad y del mondo sobrenatural en el manto de Brooklyn". En: Victoria Solanilla Demestre (ed.) Tejiendo sueños en el Cono Sul, Textiles andinos: pasado, presente y futuro, acatas del simposio ARQ-21 51 Congresso Internacional de Americas, Santiago de Chilo 14-18 julio 2003.

MALPASS, Michael A.

1983 "The Preceramic occupations of the Casma Valley, Peru". En: Daniel H. Sandweiss (ed.) Latin American Studies Program- Investigations of the Andean Past: 1-20, Cornell University, Ithaca, New York.

MASSEY, Sarah A.

1986 Sociopolitical change in the upper Ica Valley, 400 BC to AD 400: Regional states on the South Coast of Peru". $\mathrm{PhD}$ Dissertation, University of California, Los Angeles.

MAYER, Eugen Friedrich

1998 "Armas y herramientas de metal prehispanicas en Perú". Materialen zur Allgemeinen und Vergleichenden Archäologie, band 55, Verlag Phillip Von Zabern, Mainz.

MCINTYRE, Loren

1973 "The lost emmpire of the Incas". National Geogrpahic Magazine vol 144, n 6, dec. 1973: 729-786.

MEANS, Philip Ainsworth

1920 "Distribution and use of slings in Pre-columbian America". Proceedings of the United States Natural Museum, n55: 317-345.

1931 Ancient civilizations of the Andes. Charles Scribner's sons. New York and London.

MENZEL, Dorothy

1971 “Estudios arqueológicos en los valles de Ica, Pisco, Chincha y Cañete". Arqueología y Sociedad nº 6.

METRAUX, Alfred

1963 "Warfare, cannibalism and human trophies". En: J. Steward (ed.), Handbook of South American Indians, vol 5.: 383-409.

MORRIS Craig and Adriana VON HAGEN

1993 The Inka empire and its Andean origins. New York: Abbeville Press.

MUELLE, Jorge $C$.

1957 “Puntas de Pizarra pulidas del Perú". Arqueológicas. Museo Nacional de Antropologia y Arqueología, $n^{\circ}$ 1,2: 48-63, Lima.

MUJICA, Elias

1975 Excavaciones arqueológicas en Cerro de Arena: un sitio del Formativo Superior en el valle de Moche, Peru (2 tms), Thesis de Bachiller, Pontificia Universidad Catolica del Peru, Lima (mimeo).

MURÚA, don Martín

1962 [1590] Historia general del Perú, origen y descendencia de los Incas . 2 t, Colección Joyas Bibliograficas, Bibliotheca Americana Vetus", I y II, Madrid: Instituto Gonzalo Fernandez de Oviedo.

O'NEALE, L.M.

1937 "Archaeological explorations in Peru. Pt III: Textiles of the Early Nazca period". Field Museum of Natural History, Anthropology Memoirs, vol 2, n³: 119-218, Chicago.

OREFICI, Giuseppe

1993 Nasca: Arte societa del popolo dei Geoglifi. Milan: Jaca Books.

OTTERBEIN, Keith F.

2004 How war began, Texas A\&M University, Anthropologies series.

PEARSON, Mike Parker

2005 Warfare, violence and slavery in Prehistory, an inroduction. In Mike Parker Pearson, N Torpe.(eds), Warfare, violence and slavery in Prehistory. BAR Internacional Series, 1374: 19-33.

PÉREZ CALDERÓN, Ismael

1998 "Sitios del período Formativo en Santiago de Chuco, depto de la Libertad, Sierra Norte de los Andes centrales". Boletín de Arqueología PUCP n²: 127-145 
PIZZARO, Pedro

1944 [1571] Relacion del descubrimiento y conquista de los reinos del Peru, ed. Futuro, Buenos Aires.

POLITIS, Gustavo, Pablo MESSINEO, Christian KAUFLANN, Maria P. BARROS, Maria C. ALVAREZ, Violeta di PRADO y Rocío SCALISE

2005 "Persitencia ritual entre cazadores- recolectores de la llanura pampeana". Boletín de Arqueología PUCP n'9: 67-90.

POZORSKI, Shelia G. \& Thomas G.

1987 Early settlements and subsistance in the Casma valley, Per, Univ. of Iowa Press, Iowa city.

2002 "The Sechín Alto complex and its place within Casma Valley Inicial period development". En: William H Isbell and Helaine Silverman (eds.), Andean Archaeology I, theorizing variations in Andean sociopolitical organization, New York: Kluwer Academic/ Plenum Pubishers.

PROULX, Donald A.

1985 An analysis of the Early cultural sequence in the Nepeña valley, Peru, Research report n²5, Department of Anthropology, University of Massachussets, Amherst.

1998 Settlement patterns and society in South Coastal Peru: Report on a survey of the lower río Nasca and río Grande.

2001 "Ritual uses of trophy heads in ancient Nasca Society". En: Elizabeth P. Benson and Anita G. Cooks (eds.), Ritual sacrifice in ancient Peru, University of Texas Press, Austin: 118-136.

2006 A source book of Nasca iconography, University of Iowa Press, Iowa.

2007 Appendix to Proulx 1998: Artefacts, à settlement patterns and society in South Coast Peru; report on a Survey of the río Nasca and río Grande.

QUIROGA IBARROLA, Cesar A.

1958 "Ensayo monografico de la organizacion del ejército y armas empleadas por los soldados del Tahuantinsuyu y por los conquistadores españoles". Actas y Trabajos del II Congresso Nacional de Historia del Peru: 385-96 Centro de Estudios Historico-Militares del Peru, vol II.

RAVINES, Rogger

1967 "A precolumbian wound". American Antiquity, vol 32(2): 230-31.

1970 “Investigaciones antropológicas en el Perú: 1969-70". Revista del Museo Nacional XXXVI: 267-281, Lima.

1990 “La tiradera, propulsor o estólica del antiguo Pérú”. Boletín de Lima n 70, julio 1990: 29-35.

RAYMOND, Anan

1986 "Experiments in the function and performance of the weighted atlatl". Word Archaeology 18(2) Weaponry and Warfares.

RICK, John W.

2008 "Context, construction and ritual in the development of authority at Chavín de Huántar". En: William J. Conklin y Jeffrey Quilter (eds.). Chavin: Art, architecture, and culture: 3-34,Monograph 61, Los Angeles: Cotsen Institute of Archaeology at UCLA, University of California.

RIDDELL, F.y L.M.VALDEZ

1988 "Hacha y la ocupación temprana del valle de Acari". Gaceta Arqueologica Andina n4(16): 6-10, Lima.

ROE, Peter

1974 A further exploration of the Rowe Chavin seriation and its implications for North Central Coast chronology. Studies in Precolumbian Art and Archaeology, n¹3, Dumbarton Oaks Research Library and Collections; Washington, D.C.

2008 "How to build a raptor: Why the Dumbarton Oaks "Scaled Cayman" Callango textile is really a jaguaroid harpy eagle". En: William Conklin y Jeffrey Quilter (eds.) Chavín: Art, architecture, and culture: 181-216. monograph 61. Los Angeles: Cotsen Institute of Archaeology, University of California.

ROWE, John H

1962 Chavín. An inquiry into its form and meaning. New York: The Museum of Primitive Art.

1967 "Form and meaning in Chavín art". En: J. H. Rowe and D. Menzel (ed.) Peruvian archaeology: Selected readings: 72-104, Palo Alto: Peek Publications. 
ROZOY, J. G.

1992 "Le propulseur et l'arc. Chez les chasseurs préhistoriques. Techniques et démographie comparée". Paléo 4: 175-193.

SALAS, Alberto Marío

1950 La armas de la Conquista, Buenos Aires.

SAWYER, Alan R, Nathan CUMMINGS, Bruno John WASSERMANN-SAN BLAS

1954 The Nathan Cummings collection of ancient Peruvian art (formerly Wassermann San Blas Collection): handbook Chicago.

SELER, Eduard

1923 "Die Buntebemalten Gefässe von Nazca im südlichen Peru und die Hauptelemente ihrer Verzierung". Gesammelte Abhandlungen zur Amerikanischen Sprach- und Altertumbskunde n 4: 169338, Berlin, Verlag Behrend.

SHADY SOLIS, Ruth

2005 La Civilización de Caral Supe: 5000 años de Identidad Cultural en el Perú, Instituto Nacional de Cultura, Proyecto Especial Arqueológico Caral-Supe.

SHIBATA, Koishiro

2008 "El sitio de Cerro Blanco de Nepeña dentro de la dinámica interactiva del Periodo Formativo". Boletín de Arqueología PUCP n¹2: 287-315.

SILVA SANTISTEBAN, Fernando

1985 “Cajamarca en la historia del Perú". En: Fernando Silva Santisteban, Waldemar Espinoza Soriano y Rogger Ravines (eds.), Historia de Cajamarca, Instituto Nacional de Cultura, Cajamarca, Corporación de Desarrollo, tomo1: Arqueologia: 9-27.

1986 "El reino de Cuismancu". En: Fernando Silva Santisteban, Waldemar Espinoza Soriano y Rogger Ravines (eds.), Historia de Cajamarca, Instituto Nacional de Cultura, Cajamarca, Corporación de Desarrollo, tomo 2: Etnohistoria y Lingüística: 15-33.

SILVERMAN, Helaine y Donald A. PROULX.

2002 The Nascas, Blackwell Publishers Inc. Malden (Mas.), Oxford (UK).

STANDEN, Vivien G.

2003 "Bienes funerarios del cementerio Chinchorro Mooro 1: Descripción, análisis y interpretación". Chungará (Arica), 35 (2): 175-207.

STANDEN, Vivien G. y Bernardo T. ARRIAZA

2000 "Trauma in the Preceramic Coastal Populations of Northern Chile: Violence or Occupational Hazards?". Journal of Physical Anthropology n¹12: 239-49.

STANISH, Charles

1992 Ancient Andean Political Economy. University of Teas Press, Austin.

STRONG, William D. and EVANS C.

1952 "Cultural Stratigraphy in the Viru Valley, Northern Peru: The Formative and Florescent Epochs". Colombia Studies in Archaelogy and Ethnology. 4. New York.

TELLO, Julio Cesar

1960 Chavín, cultura matriz de la civilizacion andina. Lima: imprenta de la Universidad Nacional Mayor de San Marcos.

2005 Paracas, Primera parte. Clasicos Sanmarquinos, UNMSM, con presentación bibliográfica y estudios introductorios de César W. Astuhuaman Gonzales, Richard E. Daggett, Jürgen Golte, Harold Hernandez Lefranc.

TELLO, Julio y Mejia XESSPE

1979 Paracas Segunda parte; Cavernas y Necropolis. Universidad Mayor de San Marcos y Institute of Andean Research New York.

TESTART, Alain

1985 Le Communisme Primitif. I. Economie et Idéologie. Edition de la Maison des Sciences de l'Homme. Paris.

THOMPSON, Donald E.

1964 "Formative Períod Architecture in the Casma Valley, Peru". XXXV Congreso Internacional de Americanistas, actas y memorias, 1962 Vol.1: 205-212. Mexico, D.F. 
TOPIC, John R.

1989 "The Ostra Site: The Earliest Fortified Site in the New World?" En: Cultures and Conflict: Archaeological Prespectives, Diana.C. Tkaczuk and Brian.C. Vivian (eds.): 215-228, Proceedings of the Twentieth Annual Chacmool Conference, Archaeological Association of the University of Calgary.

TOPIC, John \& Theresa TOPIC

1987 "The Archaeological investigation of Andean Militarism: some cautionary observations". En: Jonathan Haas, Sheila Pozorski. \& Thomas Pozorski (eds.) The Origins and Development of the Andean States: 47-55, Cambridge, Cambridge University Press.

TRIPCEVICH, Nicholas

2006 Mobility and exchange in the south-central Andean Preceramic, insight from obsidian studies, Society for American Archaeology.

TUNG, Tiffiny, Marta CABRERA y José OCHATOMA

2007 "Cabezas trofeo Wari, rituales del cuerpo en el recinto ceremonial en "D" Conchopata", revista UNSCH. Universidad Nacional San Cristobal de Huamanga 15: 216-227.

UHLE, Max

1907 "La estólica en el Perú", Revista Historica, tomo II: 118-128, Lima.

1909 "Peruvian Throwing sticks". American Anthropologist, ns.vol11, n4, Lancaster, Pen.

URTEAGA, Horacio

1920 “Armamiento incaico: la estólica o atlatl". Mercurio Peruano, tomo III, n¹9: 79-91.

1928 “El Ejercito Incaico, su organizacion, sus armas”. En: El Perú, monografias historicas, libreria e imprensa Gil, Lima.

1931 El Imperio Incaico. Lima: Gil.

VALDEZ, Lidio

2000 "La Arqueología del valle de Acari". Boletín del Museo de Arqueología y Antropología 3(12): 19-25, UNMSM.

VELLARDE, L.C.

1980 “Arqueología del Antiguo Perú”. En: Vellarde L. C. et L. G. Lumbreras (eds.), Historia General del Ejército Peruano.

VERANO, W. John

2001 "War and Death in the Moche World: Osteological Evidence and Visual Discourse". En: Moche Society. In Moche Art and Archaeology in Ancient Peru, Joanne Pillsbury (ed). National Gallery of Art, Washington, distributed by Yale University Press, New Haven and London.

WASSERMANN SAN BLAS

1938 Cerámicas del antiguo Perú de la Colección Wassermann-San Blas, Buenos Aires

WENDT, W.E.

1964 “Die präkeramische Siedlung am Río Seco, Peru", Baessler-Archiv N.S.(2): 335-75.

WILLEY, GordonW. and John M. CORBETT

1954 Early Ancon and Early Supe Culture, Chavín Horizon Sites of the Central Peruvian Cost. Columbia University Press, NewYork.

WILSON, David J.

1988 "Desert ground drawings in the Lower Santa Valley, North Coast of Peru". American Antiquity 53: $794-804$

1999 Indigenous South Americans of the Past and Present, An Ecologic Perspective, Westview Press.

YACOVLEFF, Eugenio et Jorge MUELLE

1932 "Una Exploracion en Cerro Colorado: Informe y observaciones". Revista del Museo Nacional (Lima) 1 (2): 31-59.

YDE, Jens

1948 "Regional distribution of South American Blowgun Types". Journal de la Société des Américanistes nº 37: 275-317. 